\title{
Results on proximal and generalized weak proximal contractions including the case of iteration-dependent range sets
}

\author{
Manuel De la Sen ${ }^{1 *}$, Ravi P Agarwal ${ }^{2,3}$ and Asier Ibeas ${ }^{4}$
}

\section{"Correspondence:}

manuel.delasen@ehu.es

${ }^{1}$ Institute of Research and

Development of Processes,

University of the Basque Country,

Campus of Leioa (Bizkaia), Barrio

Sarriena, P.O. Box 644, Bilbao, Leioa 48940, Spain

Full list of author information is available at the end of the article

\begin{abstract}
This paper presents some further results on proximal and asymptotic proximal contractions and on a class of generalized weak proximal contractions in metric spaces. The generalizations are stated for non-self-mappings of the forms $T_{n}: A_{n} \rightarrow B_{n}$ for $n \in \mathbf{Z}_{0+}$ and $T: \bigcup_{j \in \mathbf{Z}_{0+}} A_{0 j} \rightarrow \bigcup_{j \in \mathbf{Z}_{0+}} B_{0 j}$, or $T: A \rightarrow\left(\bigcup B_{n}\right)$, subject to $T\left(A_{0 n}\right) \subseteq B_{0 n}$ and $T_{n}\left(A_{n}\right) \subseteq B_{n}$, such that $T_{n}$ converges uniformly to $T$, and the distances $D_{n}=d\left(A_{n}, B_{n}\right)$ are iteration-dependent, where $A_{0 n}, A_{n}, B_{0 n}$ and $B_{n}$ are non-empty subsets of $X$, for $n \in \mathbf{Z}_{0+}$, where $(X, d)$ is a metric space, provided that the set-theoretic limit of the sequences of closed sets $\left\{A_{n}\right\}$ and $\left\{B_{n}\right\}$ exist as $n \rightarrow \infty$ and that the countable infinite unions of the closed sets are closed. The convergence of the sequences in the domain and the image sets of the non-self-mapping, as well as the existence and uniqueness of the best proximity points, are also investigated if the metric space is complete. Two application examples are also given, being concerned, respectively, with the solutions through pseudo-inverses of both compatible and incompatible linear algebraic systems and with the parametrical identification of dynamic systems.
\end{abstract}

Keywords: proximal contraction; weak proximal contraction; best proximity point; set-theoretic limit; Moore-Penrose pseudo-inverse

\section{Introduction}

The characterization and study of existence and uniqueness of best proximity points is an important tool in fixed point theory concerning cyclic nonexpansive mappings including the problems of (strict) contractions, asymptotic contractions, contractive and weak contractive mappings and also in related problems of proximal contractions, weak proximal contractions and approximation results and methods [1-15]. The application of the theory of fixed points in stability issues has been proved to be a very useful tool. See, for instance, [16-18] and references therein. This paper is devoted to formulating and proving some further results for more general classes of proximal contractions. The problem of proximal contractions associated with uniformly converging non-self-mappings $\left\{T_{n}\right\} \rightrightarrows\{T\}$ of the form $T_{n}: A_{n} \rightarrow B_{n} ; \forall n \in \mathbf{Z}_{0_{+}}$, where $A_{n}$ and $B_{n}$ are in general distinct, with a settheoretic limit of the form $T: \bigcup_{j \in \mathbf{Z}_{0+}} A_{0 j} \rightarrow \bigcup_{j \in \mathbf{Z}_{0+}} B_{0 j}$, provided that the set-theoretic limits of the involved set exist and that the infinite unions of the involved closed sets are also closed. Further related results are obtained for generalized weak proximal and proximal contractions in metric spaces $[2,3,19]$, which are subject to certain parametrical 
constraints on the contractive conditions. Such constraints guarantee that the implying condition of the proximal contraction holds for the proximal sequences so that it can be removed from the analysis [1-3]. Some related generalizations are also given for non-selfmappings of the form $T: A \rightarrow\left(\bigcup B_{n}\right)$, subject to a set distance $D_{n}=d\left(A, B_{n}\right)$, where $A$ and $B_{n}$ are non-empty and closed subsets of a metric space $(X, d)$ for $n \in \mathbf{Z}_{0_{+}}$, provided that the set-theoretic limit of the sequence of sets $\left\{B_{n}\right\}$ exists as $n \rightarrow \infty$. The properties of convergence of the sequences in the domain and the image sets of the non-self-mapping, as well as the existence and uniqueness of the best proximity points, are also investigated for the different constraints and the given extension. Application examples are given related to the exact and approximate solutions of compatible and incompatible linear algebraic systems and with the parametrical identification of dynamic systems [8-11].

\subsection{Notation}

$\left\{T_{n}\right\} \rightrightarrows\{T\}$ denotes uniform convergence to a limit $T$ of the sequence $\left\{T_{n}\right\}$ of, in general, non-self-mappings $T_{n}$ from $A$ to $B ; \forall n \in \mathbf{Z}_{0+}$.

$\mathbf{Z}_{0+}$ and $\mathbf{Z}_{+}$are, respectively, the sets of non-negative and positive integer numbers and $\mathbf{R}_{0+}$ and $\mathbf{R}_{+}$are, respectively, the sets of non-negative and positive real numbers.

The notation $\left\{x_{n}\right\}$ stands for a sequence with $n$ running on $\mathbf{Z}_{0+}$ simplifying the more involved usual notation $\left\{x_{n}\right\}_{n \in \mathbf{Z}_{0+}}$. A subsequence for indexing subscripts larger than (respectively, larger than or equal to) $n_{0}$ is denoted as $\left\{x_{n}\right\}_{n>n_{0}}$ (respectively, as $\left\{x_{n}\right\}_{n \geq n_{0}}$ ).

The symbols $\neg, \vee, \wedge$ stand, respectively, for logic negation, disjunction, and conjunction.

\section{Proximal and asymptotic proximal contractions of uniformly converging non-self-mappings}

Let us establish two definitions of usefulness for the main results of this section.

Definition 2.1 Let $(A, B)$ be a pair of non-empty subsets of a metric space $(X, d)$. A mapping $T: A \rightarrow B$ is said to be:

(1) A proximal contraction if there exists a non-negative real number $\alpha<1$ such that, for all $u_{1}, u_{2}, x_{1}, x_{2} \in A$, one has

$$
d\left(u_{i}, T x_{i}\right)=D \quad(i=1,2) \quad \Rightarrow \quad d\left(u_{1}, u_{2}\right) \leq \alpha d\left(x_{1}, x_{2}\right)
$$

where $D=d(A, B)=\inf _{x \in A, y \in B} d(x, y)$.

(2) An asymptotic proximal contraction if there exists a sequence of non-negative real numbers $\left\{\alpha_{n}\right\}$, with $\alpha_{n}<1 ; \forall n \in \mathbf{Z}_{0+}$, with $\alpha_{n} \rightarrow \alpha(\in[0,1))$ as $n \rightarrow \infty$ such that, for all sequences $\left\{u_{1 n}\right\},\left\{u_{2 n}\right\},\left\{x_{1 n}\right\},\left\{x_{2 n}\right\} \subset A$,

$$
d\left(u_{n+1}, T x_{n}\right)=D \quad\left(n \in \mathbf{Z}_{0+}\right) \quad \Rightarrow \quad d\left(u_{n+2}, u_{n+1}\right) \leq \alpha_{n} d\left(x_{n+1}, x_{n}\right) ; \quad \forall n \in \mathbf{Z}_{0+} .
$$

If $x, u \in A$ satisfy $d(u, T x)=D$ then $u \in A$ and $T x \in B$ are a pair of best proximity points of $T$ in $A$ and $B$, respectively. Note that if $T: A \rightarrow B$ is an asymptotic proximal contraction and the sequence $\left\{x_{n}\right\} \subset A$ is such that $\left(x_{n+1}, T x_{n}\right) \in A \times B ; \forall n \in \mathbf{Z}_{0+}$ is a best proximity pair, then there is a subsequence $\left\{x_{n}\right\}_{n \geq n_{0}}$ of $\left\{x_{n}\right\}$ such that the relation $d\left(x_{n+2}, x_{n+1}\right) \leq$ $\alpha_{n} d\left(x_{n+1}, x_{n}\right) \leq \bar{\alpha} d\left(x_{n+1}, x_{n}\right) ; \forall n \geq n_{0}$, holds for some real constant $\bar{\alpha} \in[\alpha, 1)$. 
Some asymptotic properties of the distances between the sequences of domains and images of the sequences of non-self-mappings $T_{n}: A_{n} \rightarrow B_{n} ; \forall n \in \mathbf{Z}_{0+}$, which converge uniformly to a limit non-self-mapping $T: \bigcup_{j \in \mathbf{Z}_{0+}} A_{0 j} \rightarrow \bigcup_{j \in \mathbf{Z}_{0_{+}}} B_{0 j}$, are given and proved related to the distance between the domain and image of the limit non-self-mapping.

Lemma 2.2 Let $(X, d)$ be a metric space endowed with a homogeneous translationinvariant metric $d: X \times X \rightarrow \mathbf{R}_{0_{+}}$. Consider also a proximal non-self-mapping and a sequence of proximal non-self-mappings $T$ and $\left\{T_{n}\right\}$ defined, respectively, by $T: \bigcup_{j \in \mathrm{Z}_{0_{+}}} A_{0 j} \rightarrow$ $\bigcup_{j \in \mathbf{Z}_{0+}} B_{0 j}$, having non-empty images of its restrictions $T: \bigcup_{j \in \mathbf{Z}_{0+}} A_{0 j}\left|A_{0 n} \rightarrow \bigcup_{j \in \mathbf{Z}_{0+}} B_{0 j}\right| B_{0 n}$; $\forall n \in \mathbf{Z}_{0+}$, and $T_{n}: A_{n} \rightarrow B_{n} ; \forall n \in \mathbf{Z}_{0+}$, where $A_{n}(\neq \varnothing) \subseteq A_{0 n}$ and $A_{0 n}$ are non-empty subsets of $X$ subject to $T\left(A_{0 n}\right) \subseteq B_{0 n}$ and $T_{n}\left(A_{n}\right) \subseteq B_{n} ; \forall n \in \mathbf{Z}_{0+}$ such that the sets of best proximity points:

$$
\begin{aligned}
& A_{0 n}^{0}=\left\{x \in A_{0 n}: d(x, y)=D_{n}^{0} \text { for some } y \in B_{0 n}\right\}, \\
& B_{0 n}^{0}=\left\{y \in B_{0 n}: d(x, y)=D_{n}^{0} \text { for some } x \in A_{0 n}\right\}, \\
& A_{n}^{0}=\left\{x \in A_{n}: d(x, y)=D_{n} \text { for some } y \in B_{n}\right\}, \\
& B_{n}^{0}=\left\{y \in B_{n}: d(x, y)=D_{n} \text { for some } x \in A_{n}\right\}
\end{aligned}
$$

are non-empty, where $D_{n}^{0}=d\left(A_{0 n}, B_{0 n}\right)$ and $D_{n}=d\left(A_{n}, B_{n}\right) ; \forall n \in \mathbf{Z}_{0+}$. Let $\left\{x_{n}\right\}$ and $\left\{y_{n}\right\}$ be proximal sequences built in such a way that $x_{0} \in A_{01}, y_{0} \in A_{1}, d\left(x_{n+1}, T x_{n}\right)=D_{n}^{0}$ and $d\left(y_{n+1}, T_{n} y_{n}\right)=D_{n} ; \forall n \in \mathbf{Z}_{0+}$ and define also the error sequence $\left\{\tilde{x}_{n}\right\}$ by $\tilde{x}_{n}=y_{n}-x_{n} ; \forall n \in$ $\mathbf{Z}_{0+}$. Then the following properties hold:

(i)

$$
\begin{aligned}
& \limsup _{n \rightarrow \infty}\left(\left|D_{n+1}-D_{n+1}^{0}\right|-\bar{g}_{n+1}\right) \leq \limsup _{n \rightarrow \infty}\left(\left|D_{n+1}-D_{n+1}^{0}\right|-g_{n+1}\right) \leq 0, \\
& g_{n+1} \leq D_{n+1}+D_{n+1}^{0} ; \quad \forall n \in \mathbf{Z}_{0+}, \quad \limsup _{n \rightarrow \infty}\left(g_{n+1}-D_{n+1}-D_{n+1}^{0}\right) \leq 0,
\end{aligned}
$$

where

$$
\begin{aligned}
& g_{n+1}=d\left(x_{n+1}-T x_{n}, y_{n+1}-T_{n} y_{n}\right) ; \quad \forall n \in \mathbf{Z}_{0+}, \\
& \bar{g}_{n+1}=d\left(T x_{n}, T y_{n}\right)+d\left(T y_{n}, T_{n} y_{n}\right)+d\left(y_{n+1}, x_{n+1}\right) ; \quad \forall n \in \mathbf{Z}_{0+} .
\end{aligned}
$$

(ii) If $\left\{g_{n}\right\} \rightarrow g$ then $\lim \sup _{n \rightarrow \infty}\left(\left|D_{n}-D_{n}^{0}\right|-g\right) \leq 0$.

(iii) If $\left\{T_{n}\right\} \rightrightarrows\{T\}$ then $\lim \sup _{n \rightarrow \infty}\left(\left|D_{n}-D_{n}^{0}\right|-d\left(T x_{n}, T y_{n}\right)-d\left(y_{n+1}, x_{n+1}\right)\right) \leq 0$.

(iv) If $\left\{T_{n}\right\} \rightrightarrows\{T\},\left\{\tilde{x}_{n}\right\}=\left\{x_{n}-y_{n}\right\} \rightarrow 0$ and $T: \bigcup_{j \in \mathbf{Z}_{0+}} A_{0 j} \rightarrow \bigcup_{j \in \mathbf{Z}_{0+}} B_{0 j}$ is uniformly Lipschitzian then $\lim _{n \rightarrow \infty}\left|D_{n}-D_{n}^{0}\right|=0$.

(v) If $\left\{g_{n}\right\} \rightarrow 0$ at exponential rate $\rho \in[0,1)$, such that $g_{n} \leq C \rho^{n} g_{0}$ for some real constant $C \geq 1$, then

$$
\begin{aligned}
& \limsup _{n \rightarrow \infty} \sum_{j=0}^{n}\left|D_{j}-D_{j}^{0}\right| \leq \frac{C g_{0}}{1-\rho}, \\
& \limsup _{m \rightarrow \infty} \sum_{j=m}^{n}\left|D_{j}-D_{j}^{0}\right| \leq \frac{C \rho^{m} g_{0}}{1-\rho} ; \quad \forall m \in \mathbf{Z}_{0+}, \\
& \lim _{n, m \rightarrow \infty} \sum_{j=m}^{n}\left|D_{j}-D_{j}^{0}\right|=0 ; \quad \forall n \in \mathbf{Z}_{0+} .
\end{aligned}
$$


(vi) Assume that $\left\{g_{n}\right\}$ is non-increasing and it converges linearly to $g$ at rate $\mu \in(0,1)$.

Then

$$
\begin{aligned}
-\infty & \leq \limsup _{n \rightarrow \infty} \sum_{j=0}^{n}\left(\left|D_{j}-D_{j}^{0}\right|-n\right)-\frac{g_{0}}{1-\mu} \\
& \leq \limsup _{n \rightarrow \infty} \sum_{j=0}^{n}\left(\left|D_{j}-D_{j}^{0}\right|-g\left(1-\mu^{j}\right)\right)-\frac{g_{0}}{1-\mu} \\
& \leq \limsup _{n \rightarrow \infty} \sum_{j=0}^{n}\left(\left|D_{j}-D_{j}^{0}\right|-g_{n}\right) \leq 0 .
\end{aligned}
$$

(vii) Assume that $\left\{g_{n}\right\}$ is non-increasing and converges linearly to $g$ at rate $\mu>0$ with order $q \geq 1$. Then

$$
\begin{aligned}
-\infty & \leq \limsup _{n \rightarrow \infty} \sum_{j=0}^{n}\left(\left|D_{j}-D_{j}^{0}\right|-\mu\left(g_{n}-g\right)^{q}\right)-g \\
& \leq \limsup _{n \rightarrow \infty} \sum_{j=0}^{n}\left(\left|D_{j}-D_{j}^{0}\right|-g_{n}\right) \leq 0 .
\end{aligned}
$$

Proof Note that, since $d: X \times X \rightarrow \mathbf{R}_{0_{+}}$is a homogeneous translation-invariant metric, $x_{0} \in A_{01}, y_{0} \in A_{1}, d\left(x_{n+1}, T x_{n}\right)=D_{n}^{0}$ and $d\left(y_{n+1}, T_{n} y_{n}\right)=D_{n} ; \forall n \in \mathbf{Z}_{0+}$, one has via induction by using the constraints that $x_{n} \in A_{0 n}^{0}\left(\subset A_{0 n}\right), y_{n} \in A_{n}^{0}\left(\subset A_{n}\right) ; \forall n \in \mathbf{Z}_{+}$according to

$$
\begin{aligned}
d\left(y_{n+1}, T_{n} y_{n}\right) & =D_{n+1}=d\left(x_{n+1}+\tilde{x}_{n+1}, T_{n} y_{n}\right) \\
& \leq d\left(x_{n+1}, T x_{n}\right)+d\left(T x_{n}-x_{n+1}, T_{n} y_{n}-y_{n+1}\right) \\
& =D_{n+1}^{0}+g_{n+1} \\
& \leq D_{n+1}^{0}+d\left(T x_{n}, T y_{n}\right)+d\left(T y_{n}, T_{n} y_{n}\right)+d\left(T_{n} y_{n}, T_{n} y_{n}+x_{n+1}-y_{n+1}\right) \\
& =D_{n+1}^{0}+\bar{g}_{n+1} ; \quad \forall n \in \mathbf{Z}_{0+},
\end{aligned}
$$

and also one gets in a similar way

$$
\begin{aligned}
d\left(x_{n+1}, T x_{n}\right) & =D_{n+1}^{0}=d\left(y_{n+1}-\tilde{x}_{n+1}, T x_{n}\right) \\
& \leq d\left(y_{n+1}, T_{n} y_{n}\right)+d\left(T_{n} y_{n}, T x_{n}+y_{n+1}-x_{n+1}\right) \\
& =D_{n+1}+g_{n+1} \\
& \leq D_{n+1}+d\left(T y_{n}, T y_{n}\right)+d\left(T x_{n}, T y_{n}\right)+d\left(T x_{n}, T x_{n}+y_{n+1}-x_{n+1}\right) \\
& \leq D_{n+1}+\bar{g}_{n+1} ; \quad \forall n \in \mathbf{Z}_{0+} .
\end{aligned}
$$

Furthermore,

$$
\begin{aligned}
g_{n+1} & =d\left(x_{n+1}-T x_{n}, y_{n+1}-T_{n} y_{n}\right) \leq d\left(x_{n+1}, T x_{n}\right)+d\left(T_{n} y_{n}, y_{n+1}\right) \\
& =D_{n+1}^{0}+D_{n+1} ; \quad \forall n \in \mathbf{Z}_{0+}
\end{aligned}
$$


and properties (i)-(ii) follow directly. Also, if $\left\{T_{n}\right\} \rightrightarrows\{T\}$ then $\left\{d\left(T y_{n}, T_{n} y_{n}\right)\right\} \rightarrow 0$ and then property (iii) is proved from property (i) since

$$
\begin{aligned}
-g_{n+1} & =-d\left(x_{n+1}-T x_{n}, y_{n+1}-T y_{n}\right) \\
& \geq-d\left(x_{n+1}, y_{n+1}\right)-d\left(y_{n+1}, y_{n+1}-T y_{n}+T x_{n}\right) \\
& =-d\left(x_{n+1}, y_{n+1}\right)-d\left(T y_{n}, T x_{n}\right) ;
\end{aligned}
$$

we have

$$
\begin{aligned}
& \limsup _{n \rightarrow \infty}\left(\left|D_{n+1}-D_{n+1}^{0}\right|-d\left(x_{n+1}, y_{n+1}\right)-d\left(T y_{n}, T x_{n}\right)\right) \\
& \quad \leq \limsup _{n \rightarrow \infty}\left(\left|D_{n+1}-D_{n+1}^{0}\right|-g_{n+1}\right) \leq 0 .
\end{aligned}
$$

If, furthermore, $\left\{x_{n}-y_{n}\right\} \rightarrow 0$ and $T: \bigcup_{j \in \mathbf{Z}_{0+}} A_{0 j} \rightarrow \bigcup_{j \in \mathbf{Z}_{0+}} B_{0 j}$ is uniformly Lipschitzian in its definition domain then there is a positive real constant $k_{T}$ such that $d\left(T x_{n}, T y_{n}\right) \leq$ $k_{T} d\left(x_{n}, y_{n}\right)$; and then property (iv) follows from property (iii) since

$$
\lim _{n \rightarrow \infty}\left|D_{n}-D_{n}^{0}\right|=\limsup _{n \rightarrow \infty}\left(\left|D_{n}-D_{n}^{0}\right|-\left(1+k_{T}\right) \max \left(d\left(x_{n}, y_{n}\right), d\left(y_{n+1}, x_{n+1}\right)\right)\right)=0 .
$$

Property (v) follows from property (i) by using

$$
\sum_{j=m}^{n}\left|D_{j}-D_{j}^{0}\right| \leq \sum_{j=m}^{n} g_{j} \leq C g_{0} \sum_{j=m}^{n} \rho^{j} \leq \frac{C \rho^{m} g_{0}}{1-\rho} .
$$

Properties (vi)-(vii) follow from property (i) with

$$
\lim _{n \rightarrow \infty}\left|\frac{g_{n+1}-g}{\left(g_{n}-g\right)^{q}}\right|=\lim _{n \rightarrow \infty} \frac{g_{n+1}-g}{\left(g_{n}-g\right)^{q}}=\mu
$$

with $q=1$ and $\mu \in(0,1)$ for property (vi) since $\left\{g_{n}-g\right\}$ is non-negative and converges to zero which leads for both (vi)-(vii) to

$$
\limsup _{n \rightarrow \infty}\left(g_{n+1}-\mu\left(g_{n}-g\right)^{q}-g\right) \leq 0,
$$

and also one gets for $q=1$ and $\mu \in(0,1)$

$$
\begin{aligned}
& \limsup _{n \rightarrow \infty}\left(g_{n+1}-\mu_{n} g-(1-\mu) g\right) \\
& \quad \leq \limsup _{n \rightarrow \infty}\left(\sum_{j=0}^{n} g_{j}-g \sum_{j=0}^{n}\left(1-\mu^{j}\right)-\frac{1-\mu^{n+1}}{1-\mu} g_{0}\right) \leq 0,
\end{aligned}
$$

which together with (i) yields (vii).

It turns out that Lemma 2.2 is extendable to the condition $\left\{\bar{g}_{n}\right\} \rightarrow \bar{g}$ with the replacements $g_{n} \rightarrow \bar{g}_{n}$ and $g \rightarrow \bar{g}$. Some results on boundedness of distances from points of the domains and their images of $T_{n}: A_{n} \rightarrow B_{n} ; \forall n \in \mathbf{Z}_{0+}$, and $T: \bigcup_{j \in \mathbf{Z}_{0+}} A_{0 j} \rightarrow \bigcup_{j \in \mathbf{Z}_{0+}} B_{0 j}$ and their asymptotic closeness to the set distance are given in the subsequent result. 
Lemma 2.3 Let $(X, d)$ be a metric space. Consider two sequences $\left\{x_{n}\right\}$ and $\left\{y_{n}\right\}$ built, respectively, under the proximal non-self-mapping $\{T\}$ and under the sequence of proximal non-self-mappings $\left\{T_{n}\right\}$ of Lemma 2.2 and assume that $\left\{T_{n}\right\} \rightrightarrows\{T\}$. Then, for any given $\varepsilon \in \mathbf{R}_{+}$, there is $N=N(\varepsilon) \in \mathbf{Z}_{0+}$ such that the following properties hold:

(i) $d\left(x_{n+1}, T_{n} x_{n}\right)<D_{n}^{0}+\varepsilon, d\left(y_{n+1}, T y_{n}\right)<D_{n}+\varepsilon ; \forall n\left(\in \mathbf{Z}_{0+}\right)>N$.

(ii) If, furthermore,

$$
d\left(T y_{n}, T x_{n}\right) \leq K_{0} \max _{n-m_{n} \leq j \leq n} d\left(y_{j}, x_{j}\right)+M ; \quad \forall n \in \mathbf{Z}_{0+}
$$

for some non-negative sequences of integers $\left\{m_{n}\right\}$ with $m_{n} \leq n ; \forall n \in \mathbf{Z}_{0+}$ and some real constants $K_{0} \in[0,1)$ and $M \in \mathbf{R}_{0_{+}}$, then

$$
\begin{aligned}
& \limsup _{n \rightarrow \infty} \max _{N<j \leq n+1} d\left(x_{j}, y_{j}\right) \leq \frac{\bar{D}+M+K_{0} M^{\prime}}{1-K_{0}}, \\
& \limsup _{n \rightarrow \infty} d\left(T x_{n}, T_{n} y_{n}\right) \leq \frac{1}{1-K_{0}}\left[\left(2-K_{0}\right) \bar{D}+M+K_{0} M^{\prime}\right],
\end{aligned}
$$

where $\bar{D}=\bar{D}(N)=\max _{N<j<\infty}\left(D_{j}^{0}+D_{j}\right)$, and $M^{\prime}=M^{\prime}(N)=\max _{1 \leq j \leq N} d\left(x_{j}, y_{j}\right)$ for any given arbitrary finite $N \in \mathbf{Z}_{+}$.

Proof Assume that the first assertion fails. Then $\exists \varepsilon \in \mathbf{R}_{+}$such that $d\left(x_{n+1}, T_{n} x_{n}\right) \geq D_{n}^{0}+\varepsilon$; $\forall n \in \mathbf{Z}_{0+}$. As a result, since $d\left(x_{n+1}, T x_{n}\right)=D_{n}^{0}$ by construction and $\left\{T_{n}\right\} \rightrightarrows\{T\}$, one gets

$$
\begin{aligned}
D_{n}^{0}+\varepsilon & \leq d\left(x_{n+1}, T_{n} x_{n}\right) \leq d\left(x_{n+1}, T x_{n}\right)+d\left(T x_{n}, T_{n} x_{n}\right) \\
& =D_{n}^{0}+d\left(T x_{n}, T_{n} x_{n}\right)<D_{n}^{0}+\varepsilon / 2 ;
\end{aligned}
$$

$\forall n\left(\in \mathbf{Z}_{0_{+}}\right)>N$ and some $N \in \mathbf{Z}_{0_{+}}$, a contradiction. Then the first assertion is true.

Now, assume that the second assertion fails. Then $\exists \varepsilon \in \mathbf{R}_{+}$such that $d\left(y_{n+1}, T y_{n}\right) \geq D_{n}+$ $\varepsilon ; \forall n \in \mathbf{Z}_{0+}$. As a result, since $d\left(y_{n+1}, T_{n} y_{n}\right)=D_{n}$ by construction and $\left\{T_{n}\right\} \rightrightarrows\{T\}$, one gets

$$
\begin{aligned}
D_{n}+\varepsilon & \leq d\left(y_{n+1}, T y_{n}\right) \leq d\left(y_{n+1}, T_{n} y_{n}\right)+d\left(T_{n} y_{n}, T y_{n}\right) \\
& =D_{n}+d\left(T y_{n}, T_{n} y_{n}\right)<D_{n}+\varepsilon / 2 ;
\end{aligned}
$$

$\forall n\left(\in \mathbf{Z}_{0+}\right)>N$ and some $N \in \mathbf{Z}_{0+}$, a contradiction. Then the second assertion is also true and property (i) has been proved. To prove (ii) note that, since $\left\{T_{n}\right\} \rightrightarrows\{T\}$, for any given $\varepsilon \in \mathbf{R}_{+}$, there are $N_{i}=N_{i}(\varepsilon) \in \mathbf{Z}_{0+}$ for $i=1,2$ such that

$$
\begin{aligned}
d\left(x_{n+1}, y_{n+1}\right) & \leq D_{n}^{0}+d\left(T x_{n}, T_{n} x_{n}\right)+d\left(T_{n} y_{n}, T_{n} x_{n}\right)+D_{n+1} \\
& <D_{n+1}^{0}+D_{n+1}+\varepsilon / 3+d\left(T_{n} x_{n}, T_{n} y_{n}\right) \\
& <D_{n+1}^{0}+D_{n+1}+\varepsilon+d\left(T x_{n}, T y_{n}\right) \\
& \leq D_{n+1}^{0}+D_{n+1}+\varepsilon+K_{0} \max _{m_{n} \leq j \leq n} d\left(x_{j}, y_{j}\right)+M \\
& \leq D_{n+1}^{0}+D_{n+1}+\varepsilon+K_{0} \max _{m_{n} \leq j \leq n+1} d\left(x_{j}, y_{j}\right)+M \\
& \leq \bar{D}+M+\varepsilon+K_{0} \max _{m_{n} \leq j \leq n+1} d\left(x_{j}, y_{j}\right)
\end{aligned}
$$




$$
\begin{aligned}
& \leq \bar{D}+M+\varepsilon+K_{0}\left(\max _{m_{n}<j \leq n+1} d\left(x_{j}, y_{j}\right)-\max _{N<j \leq n+1} d\left(x_{j}, y_{j}\right)\right)+K_{0} \max _{N<j \leq n+1} d\left(x_{j}, y_{j}\right) \\
& =\bar{D}+M+\varepsilon+K_{0}\left[M^{\prime}+\max _{N<j \leq n+1} d\left(x_{j}, y_{j}\right)\right] ; \quad \forall n\left(\in \mathbf{Z}_{0+}\right)>N
\end{aligned}
$$

for some non-negative sequences of integers $\left\{m_{n}\right\}$ with $m_{n} \leq n ; \forall n \in \mathbf{Z}_{0+}$, where $d\left(T x_{n}\right.$, $\left.T_{n} x_{n}\right)<\varepsilon / 3 ; \forall n\left(\in \mathbf{Z}_{0+}\right)>N_{1}, d\left(T y_{n}, T_{n} y_{n}\right)<\varepsilon / 3 ; \forall n\left(\in \mathbf{Z}_{0_{+}}\right)>N_{2}, N=\max \left(N_{1}, N_{2}\right), \bar{D}=$ $\bar{D}(N)=\max _{N<j<\infty}\left(D_{j}^{0}+D_{j}\right)$, and $M^{\prime}$ is a non-negative real constant, which is not dependent on $n$, defined by $M^{\prime}=M^{\prime}(N)=\max _{1 \leq j \leq N} d\left(x_{j}, y_{j}\right)$. Since $K_{0} \in[0,1)$, one gets

$$
\begin{aligned}
& \max _{N<j \leq n+1} d\left(x_{j}, y_{j}\right)<\frac{\bar{D}+M+\varepsilon+K_{0} M^{\prime}}{1-K_{0}} ; \quad \forall n\left(\in \mathbf{Z}_{0+}\right)>N, \\
& \limsup _{n \rightarrow \infty} \max _{N<j \leq n+1} d\left(x_{j}, y_{j}\right) \leq \frac{\bar{D}+M+K_{0} M^{\prime}}{1-K_{0}} .
\end{aligned}
$$

On the other hand, note that

$$
\begin{aligned}
& d\left(T x_{n}, T_{n} y_{n}\right) \leq d\left(T x_{n}, y_{n+1}\right)+d\left(y_{n+1}, T_{n} y_{n}\right) \\
& \leq d\left(x_{n+1}, y_{n+1}\right)+d\left(x_{n+1}, T x_{n}\right)+D_{n}=D_{n}^{0}+D_{n}+d\left(x_{n+1}, y_{n+1}\right) \\
&<\frac{1}{1-K_{0}}\left[\left(2-K_{0}\right) \bar{D}+M+\varepsilon+K_{0} M^{\prime}\right] ; \quad \forall n\left(\in \mathbf{Z}_{0+}\right)>N, \\
& \limsup _{n \rightarrow \infty} d\left(T x_{n}, T_{n} y_{n}\right) \leq \frac{1}{1-K_{0}}\left[\left(2-K_{0}\right) \bar{D}+M+K_{0} M^{\prime}\right],
\end{aligned}
$$

and property (ii) has been proved.

By interchanging the positions of $d\left(x_{n+1}, y_{n+1}\right)$ and $d\left(T x_{n}, T_{n} y_{n}\right)$ in the triangle inequality of (2.18), it follows that

$$
\left|d\left(T x_{n}, T_{n} y_{n}\right)-d\left(y_{n+1}, x_{n+1}\right)\right| \leq D_{n}^{0}+D_{n} ; \quad \forall n \in \mathbf{Z}_{0+},
$$

so that if either $\bigcup_{n=1}^{\infty} A_{0 n}=\bigcup_{n=1}^{\infty}\left(A_{n} \cup A_{0 n}\right)$, since $A_{n} \subseteq A_{0 n} ; \forall n \in \mathbf{Z}_{0+}$ is bounded, or $\bigcup_{n=1}^{\infty}\left(B_{n} \cup B_{0 n}\right)$ is bounded, both sequences $\left\{d\left(T x_{n}, T_{n} y_{n}\right)\right\}$ and $\left\{d\left(x_{n}, y_{n}\right)\right\}$ are bounded. On the other hand, note that the non-negative sequence of integers $\left\{m_{n}\right\}$ might imply the use of an infinite memory in the upper-bounding term of (2.11) if $m_{n} \equiv a \in \mathbf{Z}_{0+} ; \forall n \in \mathbf{Z}_{0+}$ or a finite memory of such a bound if $m-m_{n} \leq \bar{m} ; \forall n \in \mathbf{Z}_{0+}$.

Definition 2.4 [3,5] Let $(A, B)$ be a pair of non-empty subsets of a complete metric space $(X, d)$. The set $A$ is said to be approximatively compact with respect to the set $B$ if every sequence $\left\{x_{n}\right\} \subset A$ such that $d\left(y, x_{n}\right) \rightarrow d(y, A)$ for some $y \in B$ has a convergent subsequence.

Theorem 2.5 Let a proximal contraction and a sequence of proximal mappings $\{T\}$ and $\left\{T_{n}\right\}$ be defined, respectively, by $T: \bigcup_{n \in \mathbf{Z}_{0+}} A_{0 n} \rightarrow \bigcup_{n \in \mathbf{Z}_{0+}} B_{0 n}$ having non-empty images of its restrictions $T: \bigcup_{j \in \mathbf{Z}_{0+}} A_{0 j}\left|A_{0 n} \rightarrow \bigcup_{j \in \mathbf{Z}_{0+}} B_{0 j}\right| B_{0 n} ; \forall n \in \mathbf{Z}_{0+}$ and $T_{n}: A_{n} \rightarrow B_{n} ; \forall n \in \mathbf{Z}_{0+}$, where $A_{n}(\neq \varnothing) \subseteq A_{0 n}$ and $A_{n}$ are subsets of $X$, where $(X, d)$ is a metric space, subject to $T\left(A_{0 n}\right) \subseteq B_{0 n}$ and $T_{n}\left(A_{n}\right) \subseteq B_{n} ; \forall n \in \mathbf{Z}_{0+}$ and the set-theoretic limits $\lim _{n \rightarrow \infty} A_{n}$, $\lim _{n \rightarrow \infty} A_{0 n}, \lim _{n \rightarrow \infty} B_{n}$ and $\lim _{n \rightarrow \infty} B_{0 n}$ of the sequences of the sets $\left\{A_{n}\right\},\left\{A_{0 n}\right\},\left\{B_{n}\right\},\left\{B_{0 n}\right\}$, 
respectively, exist and are non-empty being defined in the usual way for any sequence $\left\{Z_{n}\right\}$ of subsets $Z_{n} \subseteq X$ as:

$$
\lim _{n \rightarrow \infty} Z_{n}=\left\{z \in X:\left(z_{n}=1 \text { if } z \in Z_{n}\right) \wedge\left(z_{n}=0 \text { if } z \notin X_{n}\right) \wedge\left(\lim _{n \rightarrow \infty} z_{n}=1\right)\right\}
$$

via the binary set indicator sequences $\left\{z_{n}\right\}$, satisfy the improper set inclusion condition $\lim _{n \rightarrow \infty} A_{n} \subseteq \lim _{n \rightarrow \infty} A_{0 n}$. Assume that the sets of best proximity points $A_{0 n}^{0}, B_{0 n}^{0}, A_{n}^{0}$, and $B_{n}^{0}$ are non-empty, where $D_{n}^{0}=d\left(A_{0 n}, B_{0 n}\right)=d\left(A_{0 n}^{0}, B_{0 n}^{0}\right)$ and $D_{n}=d\left(A_{n}, B_{n}\right)=d\left(A_{n}^{0}, B_{n}^{0}\right)$; $\forall n \in \mathbf{Z}_{0+}$. Then the following properties hold:

(i) $\liminf _{n \rightarrow \infty} T\left(A_{0 n}\right) \cup \lim \sup _{n \rightarrow \infty} T\left(A_{0 n}\right) \subseteq \lim _{n \rightarrow \infty} B_{0 n}$.

The set-theoretic limits $\left(\lim _{n \rightarrow \infty} A_{0 n}\right)$ and $T\left(\lim _{n \rightarrow \infty} A_{0 n}\right)$ exist and they are non-empty and closed if the subsets $A_{0 n}$ of $X$ are all closed and $\bigcup_{n=0}^{\infty} A_{0 n}$ is closed while it satisfies the following set inclusion constraints:

$$
T\left(\lim _{n \rightarrow \infty} A_{0 n}\right) \subseteq \limsup _{n \rightarrow \infty} T\left(A_{0 n}\right) \cap \limsup _{n \rightarrow \infty} T\left(A_{0 n}\right) \subseteq \lim _{n \rightarrow \infty} B_{0 n}
$$

If, furthermore, $\lim _{n \rightarrow \infty} T\left(A_{0 n}\right)$ exists then it is non-empty and then

$$
T\left(\lim _{n \rightarrow \infty} A_{0 n}\right)=\lim _{n \rightarrow \infty} T\left(A_{0 n}\right) \subseteq \lim _{n \rightarrow \infty} B_{0 n}
$$

The set-theoretic limits $\left(\lim _{n \rightarrow \infty} A_{n}\right)$ and $T\left(\lim _{n \rightarrow \infty} A_{n}\right)$ exist and they are non-empty and closed if the subsets $A_{n}$ of $X ; \forall n \in \mathbf{Z}_{0+}$ are all closed and $\bigcup_{n=0}^{\infty} A_{n}$ is closed, and then

$$
T\left(\lim _{n \rightarrow \infty} A_{n}\right) \subseteq \limsup _{n \rightarrow \infty} T\left(A_{n}\right) \cap \limsup _{n \rightarrow \infty} T\left(A_{n}\right) \subseteq \lim _{n \rightarrow \infty} B_{n}
$$

If, furthermore, $\lim _{n \rightarrow \infty} T\left(A_{n}\right)$ exists then it is non-empty and

$$
T\left(\lim _{n \rightarrow \infty} A_{n}\right)=\lim _{n \rightarrow \infty} T\left(A_{n}\right) \subseteq \lim _{n \rightarrow \infty} B_{n}
$$

(ii) Assume that $T: \bigcup_{j \in \mathbf{Z}_{0+}} A_{0 j} \rightarrow \bigcup_{j \in \mathbf{Z}_{0+}} B_{0 j}$ is a proximal contraction and that $\left\{T_{n}\right\} \rightrightarrows\{T\}$, where $T_{n}: A_{n} \rightarrow B_{n} ; \forall n \in \mathbf{Z}_{0+}$. Then $T_{n}: A_{n} \rightarrow B_{n} ; \forall n \in \mathbf{Z}_{0+}$, is a sequence of asymptotic proximal contractions.

(iii) If the sets in sequence $\left\{A_{0 n}\right\}_{n \geq m}$, for some $m \in \mathbf{Z}_{0+}$, are closed then $\lim _{n \rightarrow \infty} A_{0 n}$ is closed and also

$$
\begin{aligned}
& \lim _{n \rightarrow \infty} d\left(x_{n+1}, T x_{n}\right)=D^{0}, \quad \lim _{n \rightarrow \infty} d\left(x_{n+1}, x_{n}\right)=0, \\
& \left\{x_{n}\right\} \rightarrow x\left(\in \lim _{n \rightarrow \infty} A_{0 n}^{0}\right), \\
& \lim _{n \rightarrow \infty} d\left(y_{n+1}, T y_{n}\right)=D, \quad \lim _{n \rightarrow \infty} d\left(y_{n+1}, y_{n}\right)=0, \\
& \left\{y_{n}\right\} \rightarrow y\left(\in \lim _{n \rightarrow \infty} A_{n}^{0}\right), \\
& \left|D^{0}-D\right| \leq d(x, y)+\liminf _{n \rightarrow \infty} d\left(T x_{n}, T y_{n}\right) \\
& \quad \leq d(x, y)+\min \left(d\left((T x)^{+},(T y)^{+}\right), d\left((T x)^{-},(T y)^{-}\right)\right)
\end{aligned}
$$


for any sequences $\left\{x_{n}\right\} \subset A_{0 n},\left\{y_{n}\right\} \subset A_{n}$ satisfying $d\left(x_{n+1}, T x_{n}\right)=D_{n+1}^{0} ; \forall n \in \mathbf{Z}_{0+}$ and $d\left(y_{n+1}, T y_{n}\right)=D_{n+1} ; \forall n\left(\geq n_{0}\right) \in \mathbf{Z}_{0+}$ for any sequences $\left\{x_{n}\right\} \subset A_{0 n},\left\{y_{n}\right\} \subset A_{n}$ being built in such a way that $d\left(x_{n+1}, T x_{n}\right)=D_{n+1}^{0} ; \forall n \in \mathbf{Z}_{0+}$ and $d\left(y_{n+1}, T y_{n}\right)=D_{n+1}$; $\forall n\left(\geq n_{0}\right) \in \mathbf{Z}_{0+}$.

(iv) If $(X, d)$ is complete and $\lim _{n \rightarrow \infty} B_{0 n}$ is approximatively compact with respect to $\lim _{n \rightarrow \infty} A_{0 n}$ then there is a convergent subsequence $\left\{T x_{n_{k}}\right\}\left(\subset \lim _{n \rightarrow \infty} B_{0 n}\right) \rightarrow T x$ where $x \in \lim _{n \rightarrow \infty} A_{0 n}^{0}$ is the limit of $\left\{x_{n}\right\}$. If $\lim _{n \rightarrow \infty} B_{n}$ is approximatively compact with respect to $\lim _{n \rightarrow \infty} A_{n}$ then there is a convergent subsequence $\left\{T y_{n_{k}}\right\}\left(\subset \lim _{n \rightarrow \infty} B_{n}\right) \rightarrow$ Ty where $y \in \lim _{n \rightarrow \infty} A_{n}^{0}$ is the limit of $\left\{y_{n}\right\}$. If $D=D^{0}$, where $D_{n}^{0} \rightarrow D^{0}$ and $D_{n} \rightarrow D$ as $n \rightarrow \infty$, and the above two approximative compactness conditions hold and, furthermore, $A_{n}$ and $A_{0 n}$ are closed; $\forall n \in \mathbf{Z}_{0+}$ and $\bigcup_{n=0}^{\infty} A_{0 n}$ and $\bigcup_{n=0}^{\infty} A_{n}$ (it suffices that $\bigcup_{n=m}^{\infty} A_{0 n}$ and $\bigcup_{n=m}^{\infty} A_{n}$ be closed for some $\left.m \in \mathbf{Z}_{0+}\right)$ are closed then $x=y$, which is then the unique best proximity point of $T$ in the limit set $\lim _{n \rightarrow \infty} A_{n}^{0}$.

Proof Note that since $\lim _{n \rightarrow \infty} A_{n}$ and $\lim _{n \rightarrow \infty} A_{0 n}$ exist, we have

$$
\begin{aligned}
& \lim _{n \rightarrow \infty} A_{n}=\liminf _{n \rightarrow \infty} A_{n}=\bigcup_{n=0}^{\infty}\left(\bigcap_{m=n}^{\infty} A_{m}\right)=\limsup _{n \rightarrow \infty} A_{n}=\bigcap_{n=0}^{\infty}\left(\bigcup_{m=n}^{\infty} A_{m}\right), \\
& \lim _{n \rightarrow \infty} A_{0 n}=\liminf _{n \rightarrow \infty} A_{0 n}=\bigcup_{n=0}^{\infty}\left(\bigcap_{m=n}^{\infty} A_{0 m}\right)=\limsup _{n \rightarrow \infty} A_{0 n}=\bigcap_{n=0}^{\infty}\left(\bigcup_{m=n}^{\infty} A_{0 m}\right) .
\end{aligned}
$$

Note also that, since $\lim _{n \rightarrow \infty} B_{0 n}$ exists, we have $\liminf _{n \rightarrow \infty} T\left(A_{0 n}\right) \cup \lim \sup _{n \rightarrow \infty} T\left(A_{0 n}\right) \subseteq$ $\lim _{n \rightarrow \infty} B_{0 n}$ since

$$
\begin{aligned}
\liminf _{n \rightarrow \infty} T\left(A_{0 n}\right) & =\bigcup_{n=0}^{\infty}\left(\bigcap_{m=n}^{\infty} T\left(A_{0 m}\right)\right) \\
& \subseteq \bigcup_{n=0}^{\infty}\left(\bigcap_{m=n}^{\infty} B_{0 m}\right)=\liminf _{n \rightarrow \infty} B_{0 n}=\lim _{n \rightarrow \infty} B_{0 n}, \\
\limsup _{n \rightarrow \infty} T\left(A_{0 n}\right) & =\bigcap_{n=0}^{\infty}\left(\bigcup_{m=n}^{\infty} T\left(A_{0 m}\right)\right) \\
& \subseteq \bigcap_{n=0}^{\infty}\left(\bigcup_{m=n}^{\infty} B_{0 m}\right)=\limsup _{n \rightarrow \infty} B_{0 n}=\lim _{n \rightarrow \infty} B_{0 n} .
\end{aligned}
$$

Also, since $\lim _{n \rightarrow \infty} B_{n}$ exists, we have $\liminf _{n \rightarrow \infty} T\left(A_{n}\right) \cup \limsup T\left(A_{n}\right) \subseteq \lim _{n \rightarrow \infty} B_{n}$, which follows under a similar reasoning. On the other hand, the existence and nonemptiness of $\lim _{n \rightarrow \infty} A_{0 n}$, by hypothesis, implies that $T\left(\lim _{n \rightarrow \infty} A_{0 n}\right)$ exists since $A_{0 n} \subset$ $\operatorname{dom} T ; \forall n \in \mathbf{Z}_{0+}$ so that

$$
\begin{aligned}
T\left(\lim _{n \rightarrow \infty} A_{0 n}\right) & =T\left(\bigcap_{n=0}^{\infty}\left(\bigcup_{m=n}^{\infty} A_{0 m}\right)\right) \\
& \subseteq \bigcap_{n=0}^{\infty}\left(\bigcup_{m=n}^{\infty} T\left(A_{0 m}\right)\right)=\limsup _{n \rightarrow \infty} T\left(A_{0 n}\right) \subseteq \lim _{n \rightarrow \infty} B_{0 n},
\end{aligned}
$$




$$
\begin{aligned}
T\left(\lim _{n \rightarrow \infty} A_{0 n}\right) & =T\left(\bigcup_{n=0}^{\infty}\left(\bigcap_{m=n}^{\infty} A_{0 m}\right)\right)=\bigcup_{n=0}^{\infty} T\left(\bigcap_{m=n}^{\infty} A_{0 m}\right) \\
& \subseteq \bigcup_{n=0}^{\infty}\left(\bigcap_{m=n}^{\infty} T\left(A_{0 m}\right)\right) \\
& =\liminf _{n \rightarrow \infty} T\left(A_{0 n}\right) \subseteq \lim _{n \rightarrow \infty} B_{0 n} .
\end{aligned}
$$

From the above set inclusion conditions it also holds that

$$
T\left(\lim _{n \rightarrow \infty} A_{0 n}\right)=\lim _{n \rightarrow \infty} T\left(A_{0 n}\right) \subseteq \lim _{n \rightarrow \infty} B_{0 n}
$$

if $\lim _{n \rightarrow \infty} T\left(A_{0 n}\right)$ exists. If the subsets $A_{0 n} ; \forall n \in \mathbf{Z}_{0+}$ are all closed and $\bigcup_{n=0}^{\infty} A_{0 n}$ is closed then $\bigcup_{n=k}^{\infty} A_{0 n}$ is closed for any $k \in \mathbf{Z}_{+}$. In order to prove that $\lim _{n \rightarrow \infty} A_{0 n}=$ $\bigcap_{n=0}^{\infty}\left(\bigcup_{m=n}^{\infty} A_{0 m}\right)$ is closed, that is, an infinite intersection of unions of infinitely many closed sets is closed, it is first proved that all those unions are closed under the given assumption that $\bigcup_{n=0}^{\infty} A_{0 n}$ is closed. Assume this not to be the case, so that there is $k \in \mathbf{Z}_{+}$ such that $\bigcup_{n=0}^{\infty} A_{0 n}=\left(\bigcup_{n=0}^{k-1} A_{0 n}\right) \cup\left(\bigcup_{n=k}^{\infty} A_{0 n}\right)$ is closed with $\bigcup_{n=k}^{\infty} A_{0 n}$ not being closed and such that $\bigcup_{n=0}^{k} A_{0 n}$ is closed, since it is the union of a finite number of closed sets. Then either $\bigcup_{n=k-1}^{\infty} A_{0 n}=A_{0, k-1} \cup\left(\bigcup_{n=k}^{\infty} A_{0 n}\right)$ is not closed or it is closed. In the second case, $\bigcup_{n=k}^{\infty} A_{0 n} \subseteq A_{0, k-1}$ since if $\bigcup_{n=k}^{\infty} A_{0 n} \supset A_{0, k-1}$ is not closed then $\bigcup_{n=k-1}^{\infty} A_{0 n}$ cannot be closed by construction. But, if $\bigcup_{n=k}^{\infty} A_{0 n} \subseteq A_{0, k-1}$ then $\bigcup_{n=k}^{\infty} A_{0 n}$ is closed, which contradicts that it is not closed, since $A_{0, k-1}$ is closed for any $k \in \mathbf{Z}_{+}$. As a result $\bigcup_{n=k}^{\infty} A_{0 n}$ being no closed for any $k \in \mathbf{Z}_{+}$implies that $\bigcup_{n=k-1}^{\infty} A_{0 n}$ is not closed. By complete induction, it follows that $\bigcup_{n=j}^{\infty} A_{0 n}$ is not closed for any $j\left(\in \mathbf{Z}_{0+}\right) \leq k$. Thus, $\bigcup_{n=0}^{\infty} A_{0 n}$ is not closed what contradicts that it is closed. As a result, since $\bigcup_{n=0}^{\infty} A_{0 n}$ is non-empty and closed, any infinite union of non-empty closed sets $\bigcup_{n=k}^{\infty} A_{0 n}$ is also non-empty and closed for any $k \in \mathbf{Z}_{0+}$ since $\bigcup_{n=0}^{\infty} A_{0 n}$ is assumed to be closed by hypothesis and it is trivially non-empty. Then $\lim _{n \rightarrow \infty} A_{0 n}=\bigcap_{n=0}^{\infty}\left(\bigcup_{m=n}^{\infty} A_{0 m}\right)$ is non-empty and closed since it is the infinite intersection of infinitely many unions of non-empty closed sets (but already proved to be non-empty and closed $)$ and there exists the set limit $T\left(\lim _{n \rightarrow \infty} A_{0 n}\right)=T\left(\bigcap_{n=0}^{\infty}\left(\bigcup_{m=n}^{\infty} A_{0 m}\right)\right)$ which is now proved to be non-empty. Proceed by contradiction by assuming that it is empty. Then there is some $x \in \lim _{n \rightarrow \infty} A_{0 n}$ such that $x \notin \operatorname{dom} T$. But then, since $x \in \lim _{n \rightarrow \infty} A_{0 n}$, $\lim _{n \rightarrow \infty} A_{0 n}=\bigcap_{n=0}^{\infty}\left(\bigcup_{m=n}^{\infty} A_{0 n}\right)$ is non-empty and closed and all the sets in the sequence $\left\{A_{0 n}\right\}$ are closed we have $x \in A_{0 n}$ for some $n \in \mathbf{Z}_{0_{+}}$so that $x \in \operatorname{dom} T$ from the definition of the non-self-mapping $T$ which contradicts the existence of $x \in \lim _{n \rightarrow \infty} A_{0 n}$ such that $x \notin \operatorname{dom} T$. It has been proved that $\lim _{n \rightarrow \infty} A_{0 n}$ is closed and $T\left(\lim _{n \rightarrow \infty} A_{0 n}\right)$ exists and it is non-empty and closed. The proof that $T\left(\lim _{n \rightarrow \infty} A_{n}\right) \subseteq \lim _{n \rightarrow \infty} B_{n}$ is similar to the above one. Now, one proves by contradiction that $T\left(\lim _{n \rightarrow \infty} A_{n}\right)$ is non-empty if $\lim _{n \rightarrow \infty} A_{n}$ is non-empty. The limit set $\lim _{n \rightarrow \infty} A_{n}$ is non-empty since the subsets $A_{n}$ of $X$; $\forall n \in \mathbf{Z}_{0+}$ are all closed and $\bigcup_{n=0}^{\infty} A_{n}$ is closed under similar arguments that those used above to prove those properties for $\lim _{n \rightarrow \infty} A_{0 n}$. Assume that $T\left(\lim _{n \rightarrow \infty} A_{n}\right)$ is empty. Since $\lim _{n \rightarrow \infty} A_{n}$ is non-empty, there is $x \in \lim _{n \rightarrow \infty} A_{n}$ such that $x \notin \operatorname{dom} T$. Since the sets in the sequence $\left\{A_{n}\right\}$ are closed, $x \in A_{n}$ and $x \in A_{0 n}$, since $A_{n} \subseteq A_{0 n}$, for some $n \in \mathbf{Z}_{0+}$. Thus, $x \in \operatorname{dom} T$, from the definition of $T$ and $T x \in T\left(A_{0 n}\right) \cap T\left(A_{n}\right) \subseteq B_{0 n} \cap B_{n}$ since $T\left(A_{n}\right) \subseteq T\left(A_{0 n}\right) \cap B_{n} \subseteq B_{0 n} \cap B_{n} \subseteq B_{0 n}$. Then $T\left(\lim _{n \rightarrow \infty} A_{n}\right)$ is non-empty since $\lim _{n \rightarrow \infty} A_{n}$ 
is non-empty. On the other hand, since $\lim _{n \rightarrow \infty} A_{n} \subseteq \lim _{n \rightarrow \infty} A_{0 n}$ we have

$$
\begin{aligned}
T\left(\lim _{n \rightarrow \infty} A_{n}\right) & =T\left(\bigcup_{n=0}^{\infty}\left(\bigcap_{m=n}^{\infty} A_{m}\right)\right) \subseteq T\left(\bigcup_{n=0}^{\infty}\left(\bigcap_{m=n}^{\infty} A_{0 m}\right)\right) \\
& \subseteq \bigcup_{n=0}^{\infty}\left(\bigcap_{m=n}^{\infty} T\left(A_{0 m}\right)\right)=\bigcup_{n=0}^{\infty}\left(\bigcap_{m=n}^{\infty} B_{0 m}\right)=\lim _{n \rightarrow \infty} B_{0 n},
\end{aligned}
$$

so that

$$
\begin{aligned}
& T\left(\lim _{n \rightarrow \infty} A_{0 n}\right) \subseteq \lim _{n \rightarrow \infty} B_{n} \cap \lim _{n \rightarrow \infty} B_{0 n} \\
& \lim _{n \rightarrow \infty} T\left(A_{n}\right) \subseteq T\left(\lim _{n \rightarrow \infty} A_{n}\right) \subseteq \lim _{n \rightarrow \infty} B_{n} \cap \lim _{n \rightarrow \infty} B_{0 n} .
\end{aligned}
$$

In the same way, it follows that $T\left(\lim _{n \rightarrow \infty} A_{n}\right)$ exists and if, in addition, $\lim _{n \rightarrow \infty} T\left(A_{n}\right)$ exists then

$$
\lim _{n \rightarrow \infty} T\left(A_{n}\right)=T\left(\lim _{n \rightarrow \infty} A_{n}\right) \subseteq \lim _{n \rightarrow \infty} B_{n}
$$

Hence, property (i) has been proved. Now, build sequences $\left\{x_{n}\right\}$ and $\left\{x_{n}^{\prime}\right\}$, and $\left\{y_{n}\right\}$ and $\left\{y_{n}^{\prime}\right\}$ in $X$ sequences built in such a way that $x_{0}, x_{0}^{\prime} \in A_{01}, y_{0}, y_{0}^{\prime} \in A_{1}, d\left(x_{n+1}, T x_{n}\right)=D_{n}^{0}$, $d\left(x_{n+1}^{\prime}, T x_{n}^{\prime}\right)=D_{n+1}^{0} d\left(y_{n+1}, T_{n} y_{n}\right)=D_{n+1}$ and $d\left(y_{n+1}^{\prime}, T y_{n}^{\prime}\right)=D_{n} ; \forall n \in \mathbf{Z}_{0+}$. It follows inductively by using those distance constraints that $x_{n}, x_{n}^{\prime} \in A_{0 n}^{0}\left(\subset A_{0 n}\right), y_{n}, y_{n}^{\prime} \in A_{n}^{0}\left(\subset A_{n}\right)$; $\forall n \in \mathbf{Z}_{+}$. Note that $\lim _{n \rightarrow \infty} A_{n} \subseteq \lim _{n \rightarrow \infty} A_{0 n}$ implies the following inclusion of limit sets $\lim _{n \rightarrow \infty} A_{n}^{0} \subseteq \lim _{n \rightarrow \infty} A_{0 n}^{0}$ of the sets of best proximity points and the four above limit sets are trivially non-empty. Since $T: \bigcup_{j \in \mathbf{Z}_{0+}} A_{0 j} \rightarrow \bigcup_{j \in \mathbf{Z}_{0+}} B_{0 j}$ is a proximal contraction:

$$
\left(d\left(x_{n+1}, T x_{n}\right)=D_{n+1}^{0} ; \forall n \in \mathbf{Z}_{0+}\right) \quad \Rightarrow \quad\left(d\left(x_{n+1}, x_{n+2}\right) \leq K d\left(x_{n}, x_{n+1}\right) ; \forall n \in \mathbf{Z}_{0+}\right)
$$

for $\left\{x_{n}\right\} \subset A_{0 n}^{0}$ and some real constant $K \in[0,1)$ and $D_{n}^{0} \rightarrow D$ as $n \rightarrow \infty$, since the limit set $\lim _{n \rightarrow \infty} A_{0 n}$ exists. On the other hand, if $\left\{T_{n}\right\}$ is a sequence of asymptotic proximal contractions $T_{n}: A_{n} \rightarrow B_{n} ; \forall n \in \mathbf{Z}_{0+}$ then there is a real sequence $\left\{K_{n}\right\}$ with a subsequence $\left\{K_{n}\right\}_{n \geq n_{0}} \subset\left[0, K^{\prime}\right) \subset[0,1)$ such that

$$
\begin{aligned}
& \left(d\left(y_{n+1}, T_{n} y_{n}\right)=D_{n+1} ; \forall n\left(\geq n_{0}\right) \in \mathbf{Z}_{0+}\right) \\
& \quad \Rightarrow \quad\left(d\left(y_{n+1}, y_{n+2}\right) \leq K^{\prime} d\left(y_{n}, y_{n+1}\right) ; \forall n\left(\geq n_{0}\right)\right)
\end{aligned}
$$

for $\left\{y_{n}\right\}_{n \geq n_{0}} \subset A_{0 n}^{0}$ and some $n_{0} \in \mathbf{Z}_{+}$and some real constant $K \in[0,1)$. Recall the following properties for logical assertions then to be used related to (2.24). Consider the logical propositions $P_{i} ; i=1,2$. Then

$$
\begin{aligned}
& \left(P_{2} \Rightarrow P_{1}\right) \quad \Leftrightarrow \quad\left(P_{1} \vee \neg P_{2}\right), \\
& \left(\neg\left(P_{2} \Rightarrow P_{1}\right)\right) \quad \Leftrightarrow \quad\left(\neg P_{1} \wedge P_{2}\right) .
\end{aligned}
$$

The condition (2.25) corresponds to (2.26a) with $P_{2} \equiv\left(d\left(y_{n+1}, T y_{n}\right)=D_{n+1} ; \forall n \in \mathbf{Z}_{+}\right)$and $P_{1} \equiv\left(d\left(y_{n+1}, y_{n+2}\right) \leq K^{\prime} d\left(y_{n+1}, y_{n+2}\right) ; \forall n \in \mathbf{Z}_{+}\right)$. It is now proved by contradiction that $\left\{T_{n}\right\}$ 
is a sequence of asymptotic proximal contractions, that is, by assuming that (2.25) is false so that its logical negation

$$
\left[\left(d\left(y_{n+1}, T_{n} y_{n}\right)>D_{n+1}\right) \vee\left(d\left(y_{n+1}, y_{n+2}\right) \leq K^{\prime} d\left(y_{n}, y_{n+1}\right)\right) ; \forall n\left(\geq n_{0}\right) \in Z_{+}\right]
$$

for $\left\{y_{n}\right\}_{n \geq n_{0}} \subset A_{0 n}^{0}$ and some $n_{0} \in \mathbf{Z}_{+}$, obtained from (2.26a)-(2.26b) versus to (2.26a), is true. Then it follows from (2.24) that for any given arbitrary $\varepsilon \in \mathbf{R}_{+}$, there are $n_{0}, n_{1}=$ $n_{1}(\varepsilon) \in \mathbf{Z}_{0+}$ such that $d\left(T y_{n+1}, T_{n} y_{n+2}\right)<\varepsilon ; \forall n \geq n_{1}$ (since $\left.\left\{T_{n}\right\} \rightrightarrows\{T\}\right)$ and (2.27) hold. Then

$$
\begin{aligned}
\left|D_{n+2}-D_{n+1}\right| & <d\left(y_{n+2}, T_{n} y_{n+1}\right) \leq d\left(y_{n+2}, y_{n+1}\right)+d\left(T_{n} y_{n+1}, T y_{n+1}\right) \\
& <K^{\prime} d\left(y_{n+1}, y_{n}\right)+d\left(T y_{n+1}, T y_{n}\right)+\varepsilon \\
& \leq K^{\prime n-n_{0}-n_{1}} d\left(y_{n_{0}+n_{1}+1}, y_{n_{0}+n_{1}}\right)+d\left(T y_{n+1}, T y_{n}\right)+\varepsilon ; \quad \forall n \geq n_{0}+n_{1} .
\end{aligned}
$$

Since $\varepsilon \in \mathbf{R}_{+}$is arbitrary, $K^{\prime} \in[0,1)$, and $D_{n} \rightarrow D$ as $n \rightarrow \infty$ since the limit set $\lim _{n \rightarrow \infty} A_{n}$ exists and $D \geq D^{0}$, since $\lim _{n \rightarrow \infty} A_{n} \subseteq \lim _{n \rightarrow \infty} A_{0 n}$, one concludes from (2.28) that

$$
\lim _{n \rightarrow \infty} d\left(y_{n+1}, y_{n+2}\right)=0, \quad\left\{y_{n}\right\} \rightarrow y\left(\in \lim _{n \rightarrow \infty} A_{n}\right), \quad \liminf _{n \rightarrow \infty} d\left(T y_{n+1}, T y_{n}\right)>0 .
$$

Since $T: \bigcup_{n \in \mathbf{Z}_{0+}} A_{0 n} \rightarrow \bigcup_{n \in \mathbf{Z}_{0+}} B_{0 n}$ and $\lim _{n \rightarrow \infty} A_{n} \subseteq \lim _{n \rightarrow \infty} A_{0 n}$, so that $y \in \lim _{n \rightarrow \infty} A_{0 n}$, since $\bigcap_{n \geq m} A_{0 n}$ is closed by hypothesis for some $m \in \mathbf{Z}_{0+}$ and $\lim _{n \rightarrow \infty} A_{0 n}$ is also closed. Then $\lim _{n \rightarrow \infty} A_{0 n} \subset \operatorname{dom} T$ so that the possibility of $T y$ being undefined is excluded and then $T y$ is defined provided that there is no finite or infinite jump discontinuities at $y$. If $T$ is continuous at $y$, then (2.29) leads to the contradiction $d(T y, T y)>0$. Otherwise, if $T$ has a (finite or infinity) jump discontinuity at $y$, with left and right limits $(T y)^{-}$and $(T y)^{+}$ $\left(\neq(T y)^{-}\right)$, then $\min \left(d\left((T y)^{-},(T y)^{-}\right), d\left((T y)^{+},(T y)^{+}\right)\right)>0$, again a contradiction is got. Thus, (2.27) is false so that its negation (2.22) is true. Then $\left\{T_{n}\right\}$ is a sequence of asymptotic proximal contractions which converge uniformly to the proximal contraction $T$. Hence, property (ii) has been proved.

Property (iii) is proved by taking into account also (2.24) and the constraints $\lim _{n \rightarrow \infty} A_{0 n}^{0} \subseteq \lim _{n \rightarrow \infty} A_{0 n}$ and $\lim _{n \rightarrow \infty} A_{n}^{0} \subseteq \lim _{n \rightarrow \infty} A_{n} \subseteq \lim _{n \rightarrow \infty} A_{0 n}$ together with the fact that, since $\bigcap_{n \geq m} A_{0 n}$ is closed, $\lim _{n \rightarrow \infty} A_{0 n}$ is closed. Note that the conditions of $A_{0 n}$, $A_{n}, n \in \mathbf{Z}_{0+}$ being closed and $\bigcup_{n=0}^{\infty} A_{0 n}$ and $\bigcup_{n=0}^{\infty} A_{n}$ being closed can be relaxed in property (i) to closeness of the sets $A_{0 n}, A_{n}, n(\geq m) \in \mathbf{Z}_{0+}$ and $\bigcup_{n=m}^{\infty} A_{0 n}$ and $\bigcup_{n=m}^{\infty} A_{n}$ for some $m \in \mathbf{Z}_{0+}$ being closed while keeping the corresponding result. Assume this not to be the case. Now, take a subsequence $\left\{A_{0 n_{k}}\right\}$ of (non-empty closed) subsets of $X$ such that there is $x \in X$ such that $x \in \operatorname{fr}\left(\lim _{n \rightarrow \infty} A_{0 n}\right), x \notin \lim _{n \rightarrow \infty} A_{0 n}$, since $\lim _{n \rightarrow \infty} A_{0 n}$ is not closed, and $x \in A_{0 n_{k}}$, the indicator variable of $x$ in any subset in the sequence $\left\{A_{0 n_{k}}\right\}$ is $x_{0 n_{k}}=1$ then $x \in \lim _{k \rightarrow \infty} A_{0 n_{k}}$, since $\lim _{k \rightarrow \infty} x_{0 n_{k}}=1$, and $x \notin \lim _{n \rightarrow \infty} A_{0 n}$ which contra$\operatorname{dicts} \lim _{n \rightarrow \infty} A_{0 n}=\lim _{k \rightarrow \infty} A_{0 n_{k}}$. Thus, $\lim _{n \rightarrow \infty} A_{0 n}$ is non-empty and closed. Then one obtains (2.21)-(2.23).

On the other hand, since $D_{n}^{0} \rightarrow D^{0}$ as $n \rightarrow \infty$ and $\lim _{n \rightarrow \infty} B_{0 n}$ is approximatively compact with respect to $\lim _{n \rightarrow \infty} A_{0 n}$ for some sequence $\left\{x_{n}^{0}\right\} \subset \lim _{n \rightarrow \infty} A_{0 n}$

$$
d\left(T x_{n}^{0}, x\right) \rightarrow d\left(\lim _{n \rightarrow \infty} B_{0 n}, x\right)=D^{0} \quad \text { as } n \rightarrow \infty
$$


with $x \in \lim _{n \rightarrow \infty} B_{0 n}$. From property (i), $T\left(\lim _{n \rightarrow \infty} A_{n}\right) \subseteq \lim _{n \rightarrow \infty} B_{n} \subseteq \lim _{n \rightarrow \infty} B_{0 n} \times$ $T\left(\lim _{n \rightarrow \infty} A_{0 n}\right) \subseteq \lim _{n \rightarrow \infty} B_{0 n}, T\left(\lim _{n \rightarrow \infty} A_{n}\right) \subseteq \lim _{n \rightarrow \infty} B_{n}$. Then there is a subsequence $\left\{T x_{n_{k}}^{0}\right\}\left(\subset\left\{T x_{n}^{0}\right\}\right) \rightarrow z_{x} \in \operatorname{cllim}_{n \rightarrow \infty} B_{0 n}$ since $\lim _{n \rightarrow \infty} B_{0 n}$ is closed and it is obvious that $z_{x} \in \mathrm{cllim}_{n \rightarrow \infty} B_{0 n}^{0}\left(=\lim _{n \rightarrow \infty} B_{0 n}\right)$ so that $\mathrm{cllim}_{n \rightarrow \infty} B_{0 n}^{0} \neq \varnothing$. Assume that $\lim _{n \rightarrow \infty} B_{0 n}^{0}$ is empty then the best proximity point $z_{x} \notin \lim _{n \rightarrow \infty} B_{0 n}^{0}$, a contradiction so that $\lim _{n \rightarrow \infty} B_{0 n}^{0}$ is non-empty and it is closed since it is on the boundary of $\lim _{n \rightarrow \infty} B_{0 n}^{0}$ which is then nonempty and closed. But $\left\{x_{n}^{0}\right\} \rightarrow x\left(\in \lim _{n \rightarrow \infty} A_{0 n}\right)$. Since $\left\{x_{n}^{0}\right\}$ is convergent all its subsequences are convergent to the same limit so that $\left\{x_{n_{k}}^{0}\right\} \rightarrow x$. Thus, $z_{x}=T x$. Under a similar reasoning, it can be proved under the second given approximative compactness condition that $\left\{T y_{n_{k}}^{0}\right\}\left(\subset\left\{T y_{n}^{0}\right\}\right) \rightarrow z_{y}=T y \in\left(\operatorname{cllim}_{n \rightarrow \infty} B_{n}\right)$ with $\lim _{n \rightarrow \infty} B_{n}^{0}$ being non-empty and closed. If the above both approximative compactness conditions jointly hold and $D=D^{0}$ then one gets from the contractive condition for the proximal non-self-mapping $T$ that for any given $n \in \mathbf{Z}_{0+}$ :

$$
D=d\left(x_{n+1}^{0}, T x_{n}^{0}\right)=\left(y_{n+1}^{0}, T y_{n}^{0}\right) \quad \Rightarrow \quad d\left(x_{n+1}^{0}, y_{n+1}^{0}\right) \leq K d\left(x_{n}^{0}, y_{n}^{0}\right)
$$

so that $\left\{x_{n}^{0}\right\} \rightarrow x$ and $\left\{y_{n}^{0}\right\} \rightarrow y$ implies $\left\{d\left(x_{n}^{0}, y_{n}^{0}\right)\right\} \rightarrow d(x, y)$ so that $(1-K) d(x, y) \leq 0$ holds what implies $x=y$, which has to be necessarily unique from the identity, itself. Hence, property (iv) has been proved.

Remark 2.6 Note that the conditions of $A_{0 n}, A_{n}, n \in \mathbf{Z}_{0+}$ being closed and the infinite countable unions $\bigcup_{n=0}^{\infty} A_{0 n}$ and $\bigcup_{n=0}^{\infty} A_{n}$ being closed can be relaxed in Theorem 2.5 (property (i)) to the closeness of the sets $A_{0 n}, A_{n}, n(\geq m) \in \mathbf{Z}_{0+}$ and $\bigcup_{n=m}^{\infty} A_{0 n}$ and $\bigcup_{n=m}^{\infty} A_{n}$ for some $m \in \mathbf{Z}_{0+}$ being closed while keeping the corresponding result.

The following remark is of interest; it concerns a condition of validity of the assumption that a countable union of closed sets is closed used in Theorem 2.5.

Remark 2.7 It can be pointed out that a sufficient condition for the infinite countable union of closed subsets $\bigcup_{n=0}^{\infty} A_{0 n}$ (respectively, $\left.\bigcup_{n=0}^{\infty} A_{n}\right)$ of a topological space $\left(X,\left\{B_{i}\right\}\right)$ to be closed is that $X$ has the local finiteness property, that is, each point in $X$ has a neighborhood which intersects only finitely many of the closed sets in $\left\{A_{0 n}\right\}$ (respectively, in $\left\{A_{n}\right\}$ ) ([20], pp.29-31). This property can also be applied to a metric space $(X, d)$ since metric spaces are specializations of topological spaces where the metric is used to define the open balls of the topology. More general results guaranteeing that the infinite countable union of closed sets is closed, and equivalently that the infinite countable intersection of open sets is open, stand also for Alexandrov spaces (topological spaces under topologies which are uniquely determined by their specialization preorders) and for P-spaces (the intersection of countably many neighborhoods of each point of the space is also a neighborhood of such a point).

\section{Weak proximal contractions of uniformly converging non-self-mappings}

Let us establish two definitions of usefulness for the main results of this section.

Definition 3.1 Let $(A, B)$ be a pair of non-empty subsets of a metric space $(X, d)$. A mapping $T: A \rightarrow B$ is said to be: 
(1) A generalized asymptotic weak proximal contraction if there are sequences of non-negative real numbers $\left\{\alpha_{n}\right\}$, with $\alpha_{n} \in[0, \infty) ; \forall n \in \mathbf{Z}_{0+}$ and $\alpha_{n} \rightarrow \alpha(\in[0,1))$ as $n \rightarrow \infty$; and $\left\{\beta_{n}\right\}$, with $\beta_{n} \in[0, \infty) ; \forall n \in \mathbf{Z}_{0+}$ and $\beta_{n} \rightarrow \beta(\in[0, \infty))$ as $n \rightarrow \infty$ such that, for all sequences $\left\{u_{1}\right\},\left\{u_{2}\right\},\left\{x_{1}\right\},\left\{x_{2}\right\} \in A$ :

$$
\begin{gathered}
{\left[d\left(u_{i}, T x_{i}\right)=D(i=1,2)\right] \wedge\left[d\left(x_{1}, T x_{1}\right) \leq\left(1+\alpha_{n}+\beta_{n}\right) d\left(x_{1}, x_{2}\right)+D\right]} \\
\quad \Rightarrow \quad d\left(u_{1}, u_{2}\right) \leq \alpha_{n} d\left(x_{1}, x_{2}\right)+\beta_{n}\left[d\left(T x_{1}, x_{2}\right)-D\right] ; \quad \forall n \in \mathbf{Z}_{0+} .
\end{gathered}
$$

(2) A generalized weak proximal contraction [2, 3], if (3.1) holds with non-negative real constants $\alpha_{n}=\alpha<1$ and $\beta_{n}=\beta<\infty ; \forall n \in \mathbf{Z}_{0+}$.

(3) $T: A \rightarrow\left(\bigcup B_{n}\right)$ is a strongly generalized asymptotic weak proximal contraction if:

(a) $A_{0}$ and $B_{n}$ with $D_{n}=d\left(A, B_{n}\right) ; \forall n \in \mathbf{Z}_{0+}$ are non-empty and $T\left(A_{0}\right) \subseteq B_{0 n}$; $\forall n \in \mathbf{Z}_{0+}$.

(b)

$$
d\left(u_{1 n}, u_{2 n}\right) \leq \alpha_{n} d\left(x_{1 n}, x_{2 n}\right)+\beta_{n}\left[d\left(T x_{1 n}, x_{2 n}\right)-D_{n}\right] ; \quad \forall n \in \mathbf{Z}_{0+}
$$

for any sequences $\left\{x_{i n}\right\} \subset A$ and $\left\{u_{i n}\right\} \subset B_{n}$ such that $d\left(u_{i n}, T x_{i n}\right)=D_{n}(i=1,2)$; $\forall n \in \mathbf{Z}_{0+}$ and $\left\{\alpha_{n}\right\},\left\{\beta_{n}\right\}$ are real non-negative sequences which satisfy $\alpha=\lim \sup _{n \rightarrow \infty} \alpha_{n}<1$ and

$$
\beta=\limsup _{n \rightarrow \infty} \beta_{n}<\infty \quad \text { with } \mu=(\alpha+\beta)(1+\beta)+\beta<1 .
$$

(c) The sequence of set distances $\left\{D_{n}\right\}$ converges and $\left\{D_{n}-D_{n}^{0}\right\} \rightarrow 0$, where

$$
D_{n}^{0} \geq d\left(x_{1 n}, T x_{1 n}\right)-\left(1+\alpha_{n}+\beta_{n}\right) d\left(x_{1 n}, x_{2 n}\right) ; \quad \forall n \in \mathbf{Z}_{0+} .
$$

Note if $\beta=0$ in Definition 3.1(2), one has the subclass of weak proximal contractions. In this case, one gets by making $x_{n+1}=u_{n} ; \forall n \in \mathbf{Z}_{0+}$ that $d\left(x_{n}, x_{n+1}\right) \leq \alpha^{n} d\left(x_{0}, x_{1}\right)$; $\forall n \in \mathbf{Z}_{0+}$, so that $d\left(x_{n}, x_{n+1}\right) \rightarrow 0$ as $n \rightarrow \infty$, since $\alpha<1$, provided that $d\left(u_{n}, T x_{n}\right)=D$ and $d\left(x_{n}, T x_{n}\right) \leq(1+\alpha) d\left(x_{n}, x_{n+1}\right)+d\left(u_{n}, T x_{n}\right) ; \forall n \in \mathbf{Z}_{0+}$ implying $d\left(x_{n}, T x_{n}\right) \rightarrow D$ as $n \rightarrow \infty$ and under the conditions that $\left\{x_{n}\right\} \subset A$ and $\left\{T x_{n}\right\} \subset B$ converge they should necessarily converge to best proximity points. Note that Definition 3.1(1) relaxes Definition 3.1(2) and Definition 3.1(3) allows considering weak proximal contractions with sequences built from non-self-mappings which have iteration-dependent image sets.

The following results hold.

Proposition 3.2 Let $A$ and $B_{n} ; \forall n \in \mathbf{Z}_{0+}$ be non-empty subsets of a metric space $(X, d)$. Assume that $T: A \rightarrow\left(\bigcup B_{n}\right)$, such that $A_{0}$ is non-empty and $T\left(A_{0}\right) \subseteq B_{0 n} ; \forall n \in \mathbf{Z}_{0+}$, with $D_{n}=d\left(A, B_{n}\right) ; \forall n \in \mathbf{Z}_{0+}$ satisfies the contractive condition:

$$
d\left(x_{n+1}, x_{n+2}\right) \leq \alpha d\left(x_{n+1}, x_{n}\right)+\beta\left(d\left(T x_{n}, x_{n+1}\right)-D_{n}\right) ; \quad \forall n \in \mathbf{Z}_{+} .
$$


(i)

$$
d\left(x_{n+1}, x_{n+2}\right) \leq \mu^{n+1} d\left(x_{0}, x_{1}\right)+\beta \sum_{k=0}^{n} \mu^{n-k}\left(D_{k}^{0}-D_{k}\right) ; \quad \forall n \in \mathbf{Z}_{+}
$$

which is bounded for any finite $x_{0} \in A$ if $\mu \leq 1$ and $\sum_{k=0}^{n} \mu^{n-k}\left(\left|D_{k}-D_{k}^{0}\right|\right)<\infty$, where $\mu=(\alpha+\beta)(1+\beta)+\beta$, and the sequence $\left\{D_{n}^{0}\right\}$ satisfies (3.2b) which can be relaxed to (3.5) below

$$
D_{n}^{0} \geq d\left(x_{n}, T x_{n}\right)-(1+\alpha+\beta) d\left(x_{n}, x_{n+1}\right) ; \quad \forall n \in \mathbf{Z}_{0+} .
$$

(ii) If (3.3) holds, subject to (3.5), with $\mu<1$ then

$$
\begin{aligned}
& d\left(x_{n}, x_{n+1}\right) \leq \mu^{n} d\left(x_{0}, x_{1}\right)+\frac{1-\mu^{n}}{1-\mu} \beta \sup _{0 \leq k \leq n+1}\left|D_{k}-D_{k}^{0}\right|, \\
& \limsup _{n \rightarrow \infty}\left(d\left(x_{n}, x_{n+1}\right)-\frac{\beta}{1-\mu}\left(\sup _{0 \leq k \leq n}\left|D_{k}-D_{k}^{0}\right|\right)\right) \leq 0, \\
& \limsup _{n \rightarrow \infty}\left(\left|d\left(x_{n+1}, T x_{n}\right)-d\left(x_{n}, T x_{n}\right)\right|-d\left(x_{n}, x_{n+1}\right)\right) \leq 0, \\
& \limsup _{n \rightarrow \infty}\left(\left|d\left(x_{n+1}, T x_{n}\right)-d\left(x_{n}, T x_{n}\right)\right|-\frac{\beta}{1-\mu} \sup _{0 \leq k \leq n}\left|D_{k}-D_{k}^{0}\right|\right) \leq 0, \\
& \lim _{n \rightarrow \infty} d\left(x_{n}, x_{n+1}\right)=0 ; \quad \lim _{n \rightarrow \infty}\left(\left|d\left(x_{n+1}, T x_{n}\right)-d\left(x_{n}, T x_{n}\right)\right|\right)=0 \\
& \text { if }\left|D_{n}-D_{n}^{0}\right| \rightarrow 0 \text { as } n \rightarrow \infty .
\end{aligned}
$$

(iii) If (3.3) holds subject to (3.5) with $\mu<1$ then

$$
\begin{aligned}
& \liminf _{n \rightarrow \infty}\left[\min \left(d\left(x_{n}, T x_{n}\right)-D_{n}, d\left(x_{n+1}, T x_{n}\right)-D_{n+1}\right)\right] \geq 0, \\
& \limsup _{n \rightarrow \infty}\left(d\left(x_{n}, T x_{n}\right)-D_{n}^{0}-\frac{\beta(1+\alpha+\beta)}{1-\mu}\left(\sup _{0 \leq k \leq n}\left|D_{k}-D_{k}^{0}\right|\right)\right) \leq 0, \\
& \limsup _{n \rightarrow \infty}\left(d\left(x_{n+1}, T x_{n}\right)-D_{n}^{0}-\frac{\beta(2+\alpha+\beta)}{1-\mu}\left(\sup _{0 \leq k \leq n}\left|D_{k}-D_{k}^{0}\right|\right)\right) \leq 0 .
\end{aligned}
$$

(iv) If $\mu<1$ and $\left|D_{n}-D_{n}^{0}\right| \rightarrow 0$ as $n \rightarrow \infty$ then the limits below exist and are identical:

$$
\begin{aligned}
\lim _{n \rightarrow \infty}\left(d\left(x_{n}, T x_{n}\right)-D_{n}^{0}\right) & =\lim _{n \rightarrow \infty}\left(d\left(x_{n}, T x_{n}\right)-D_{n}\right)=\lim _{n \rightarrow \infty}\left(d\left(x_{n}, T x_{n}\right)-D_{n}^{0}\right) \\
& =\lim _{n \rightarrow \infty}\left(d\left(x_{n+1}, T x_{n}\right)-D_{n}\right) .
\end{aligned}
$$

If (3.3) holds, subject to (3.5), with $\mu<1,\left\{D_{n}^{0}\right\} \rightarrow D$ and $\left\{D_{n}\right\} \rightarrow D$ then $\lim _{n \rightarrow \infty} d\left(x_{n}, T x_{n}\right)=\lim _{n \rightarrow \infty} d\left(x_{n+1}, T x_{n}\right)=D$.

Proof Since $d\left(A, B_{n}\right)=D_{n}$ we have $d\left(T x_{n}, x_{n+1}\right) \geq D_{n} ; \forall n \in \mathbf{Z}_{0+}$. Also, if follows from (3.5) and (3.3) with $\mu=(\alpha+\beta)(1+\beta)+\beta$ that (3.4) holds since

$$
\begin{aligned}
d\left(x_{n+2}, x_{n+1}\right) & \leq \alpha d\left(x_{n+1}, x_{n}\right)+\beta\left(d\left(T x_{n}, x_{n}\right)+d\left(x_{n}, x_{n+1}\right)-D_{n}\right) \\
& =(\alpha+\beta) d\left(x_{n+1}, x_{n}\right)+\beta\left(d\left(T x_{n}, x_{n}\right)-D_{n}\right)
\end{aligned}
$$




$$
\begin{aligned}
& \leq \mu d\left(x_{n+1}, x_{n}\right)+\beta\left(D_{n}^{0}-D_{n}\right) \\
& \leq \mu^{n+1} d\left(x_{0}, x_{1}\right)+\beta \sum_{k=0}^{n} \mu^{n-k}\left(D_{k}^{0}-D_{k}\right) ; \quad \forall n \in \mathbf{Z}_{+}
\end{aligned}
$$

for any given $x_{0} \in A$. If $\mu \leq 1$ and $\sum_{k=0}^{n} \mu^{n-k}\left(\left|D_{k}-D_{k}^{0}\right|\right)<\infty$ then the sequence $\left\{d\left(x_{n}, x_{n+1}\right)\right\}$ is bounded. Thus, property (i) has been proved. The relations (3.6) and (3.7) of property (ii) follow directly from (3.4) of property (i) if $\mu<1$. On the other hand, the triangle inequality and (3.5) lead to (3.11) since

$$
\left|d\left(x_{n+1}, T x_{n}\right)-d\left(x_{n}, T x_{n}\right)\right| \leq d\left(x_{n}, x_{n+1}\right) .
$$

The relation (3.9) follows from (3.7) and (3.8). To prove (3.10), note that if $\lim _{n \rightarrow \infty}\left(D_{n}-\right.$ $\left.D_{n}^{0}\right)=0$, then for any given $\varepsilon \in \mathbf{R}_{+}$, there is $m=m(\varepsilon) \in \mathbf{Z}_{0+}$ such that $\sup _{m \leq k \leq n+m+1} \mid D_{k}-$ $D_{k}^{0} \mid<\varepsilon$ for any $n\left(\in \mathbf{Z}_{+}\right) \geq m$ and then, from (3.10), $\lim \sup _{n \rightarrow \infty} d\left(x_{n+1}, x_{n}\right) \leq \frac{\beta \varepsilon}{1-\mu}$. Since $\varepsilon$ is arbitrary, the limit $\lim _{n \rightarrow \infty} d\left(x_{n}, x_{n+1}\right)$ exists and $\lim _{n \rightarrow \infty} d\left(x_{n}, x_{n+1}\right)=0$. This property and (3.8) yield directly $\lim _{n \rightarrow \infty}\left(\left|d\left(x_{n+1}, T x_{n}\right)-d\left(x_{n}, T x_{n}\right)\right|\right)=0$ and then property (ii) has been fully proved. To prove property (iii), note that (3.11) holds directly from $d\left(A, B_{n}\right)=D_{n}$; $\forall n \in \mathbf{Z}_{0+}$ and $\left\{x_{n}\right\} \subset A$. Also, (3.5) leads to (3.12) by taking into account (3.7). The relation (3.13) follows from (3.7), (3.12), and the relation

$$
d\left(x_{n+1}, T x_{n}\right) \leq d\left(x_{n}, T x_{n}\right)+d\left(x_{n+1}, x_{n}\right) ; \quad \forall n \in \mathbf{Z}_{0+} .
$$

Hence, property (iii) has been proved. Property (iv) is a direct consequence of property (iii) for the case when $d\left(x_{n}, x_{n+1}\right) \rightarrow 0$ and $\left|D_{n}-D_{n}^{0}\right| \rightarrow 0$ as $n \rightarrow \infty$ including its particular sub-case when $\left\{D_{n}^{0}\right\} \rightarrow D$ and $\left\{D_{n}\right\} \rightarrow D$.

Note that Proposition 3.2 is applicable to the strongly generalized asymptotic weak proximal contraction of Definition 3.1(3) which do not need the fulfilment of the implying part of the logic proposition of Definition 3.1(1)-(2) but the distances of sequences of sets satisfy (3.2b) or, at least, (3.5). The subsequent result is concerned with the existence and uniqueness of best proximity points if, in addition to the assumptions of Proposition 3.2, the set-theoretic limit of the sequence $\left\{B_{n}\right\}$ exists and is closed and approximatively compact with respect to $A$.

Theorem 3.3 Under all the assumptions of Proposition 3.2 and property (iii), equation (3.10), assume also that $(X, d)$ is complete, that $A$ and $B_{n} ; \forall n \in \mathbf{Z}_{0+}$, are non-empty subsets of $X$ such that $A$ is closed, $A_{0}$ is non-empty, the set-theoretic limit $B:=\lim _{n \rightarrow \infty} B_{n}$ exists, is closed and approximatively compact with respect to $A$ (or the weaker condition that $A_{0}$ is closed) and $T\left(A_{0}\right) \subseteq B_{0}$. Assume also that the non-self-mapping restriction $T: A \mid A_{1} \rightarrow$ $\left(\cup B_{n}\right) \mid B$, for some subset $A_{1} \subset A$, which contains the set of best proximity points $A_{0}$, is a strongly generalized asymptotic weak proximal contraction. Then $T: A \mid A_{1} \rightarrow B$ has a unique best proximity point if $\mu<1$.

Proof Since $d\left(x_{n+1}, x_{n}\right) \rightarrow 0$ as $n \rightarrow \infty,\left\{x_{n}\right\} \rightarrow x$ from (3.10). Since $\left\{x_{n}\right\} \subset A$ and $A$ is closed we have $x \in A$. Since $D_{n} \leq d\left(x_{n+1}, T x_{n}\right)=\left\{d\left(x, T x_{n}\right)\right\}(\rightarrow D)$ since $\left\{D_{n}\right\} \rightarrow D$, because $\left\{B_{n}\right\} \rightarrow B$; and $\left|D_{n}-d\left(x_{n}, T x_{n}\right)\right| \leq d\left(x_{n}, x_{n+1}\right) ; \forall n \in \mathbf{Z}_{0+}$. Since $B$ is approximatively compact 
with respect to $A$ and $\left\{x_{n}\right\} \subset A$, there are $y \in A_{0}$ and a sequence $\left\{\bar{x}_{n}\right\} \subset A$, such that $\left\{\bar{x}_{n}-\right.$ $\left.x_{n}\right\} \rightarrow 0$, then $\left\{\bar{x}_{n}\right\} \rightarrow x$ since $\left\{x_{n}\right\} \rightarrow x$, and $\left\{T x_{n}\right\} \subset B$ such that one gets as $n \rightarrow \infty$ :

$$
d\left(\bar{x}_{n}, T \bar{x}_{n}\right) \rightarrow d(y, B)=D ; \quad d\left(\bar{x}_{n}, B\right) \rightarrow d(y, B)=D ; \quad d\left(x_{n}, B\right) \rightarrow d(y, B)=D,
$$

$\left\{d\left(x_{n}, T x_{n}\right)\right\} \rightarrow D,\left\{d\left(x_{n+1}, T x_{n}\right)\right\} \rightarrow D$ and $\left\{d\left(x, T x_{n}\right)\right\} \rightarrow D$. Since $B$ is approximatively compact with respect to $A$ and $\left\{x_{n}\right\} \subset A$, the sequence $\left\{T x_{n}\right\} \subset \bigcup B_{n}$, such that $T x_{n} \in B_{n}$, has a convergent subsequence $\left\{T x_{n_{k}}\right\} \rightarrow z \in B$, since $B$ is also closed and both $\left\{T x_{n_{k}}\right\}$ and $\left\{T x_{n_{k}}\right\}$ have the same limit $z \in B$. Also, $z \in \operatorname{cl} B_{0}$ and $d\left(x, T x_{n_{k}}\right) \rightarrow D(=d(x, z))$ as $k \rightarrow \infty$ so that $x$ is a best proximity point of $T: A \mid A_{1} \rightarrow B$. Note that since the limit set $B$ exists, it is by construction the infinite union of intersections of the form $B=\bigcup_{n=0}^{\infty} \bigcap_{m \geq n}^{\infty} B_{m}$ so that $B_{0} \subseteq B \subseteq \bigcup B_{n}$ so that there is a restriction $T: A\left|A_{1} \rightarrow\left(\bigcup B_{n}\right)\right| B$ for some $A_{1} \subseteq A$ which is non-empty. Assume not so that $A_{1}=\varnothing$. If $A_{1}=\varnothing$ then $A_{0}$ is also empty which is impossible then $A_{1} \neq \varnothing$. It is now proved by contradiction that the best proximity point is unique. Assume this not to be the case so that there are two best proximity points $x, y$ such that there are two sequences $\left\{x_{n}\right\} \rightarrow x$ and $\left\{y_{n}\right\} \rightarrow y$ contained in $A$. Since $T: A\left|A_{1} \rightarrow\left(\bigcup B_{n}\right)\right| B$ is a strongly generalized asymptotic weak proximal contraction, one gets from the implied logic proposition of (3.1) with $u=x$ and $v=y$ and $D_{n}=D$ that

$$
\begin{aligned}
(1-\alpha) d(x, y) & \leq \beta(d(T x, y)-D) \leq \beta d(T x, x)+\beta d(x, y)-\beta D \\
& =\beta d(x, y),
\end{aligned}
$$

which fails for $0 \leq \beta<1-\alpha$ if $x \neq y$. Thus, $x=y$.

Closely to Theorem 3.3, the following result can be proved.

Theorem 3.4 Let $A$ and $B_{n} ; \forall n \in \mathbf{Z}_{0+}$ be non-empty closed subsets of a complete metric space $(X, d)$. Assume that $T: A \rightarrow\left(\bigcup B_{n}\right)$ is a weakly generalized asymptotic weak proximal contraction, such that $A_{0}$ is non-empty and $T\left(A_{0}\right) \subseteq B_{0 n} ; \forall n \in \mathbf{Z}_{0+}$, with $D_{n}=d\left(A, B_{n}\right)$ and $T(A) \cap B_{n} \neq \varnothing ; \forall n \in \mathbf{Z}_{0+}$. Assume also that the set limit $B:=\lim _{n \rightarrow \infty} B_{n}$ exists, is closed and approximatively compact with respect to $A$, or instead, the weaker condition that $A_{0}$ is closed. Then $T: A \rightarrow\left(\bigcup B_{n}\right)$ has a unique best proximity point.

\section{Examples}

Two examples are described to the light of proximal contractions. The first one is concerned with the solution of algebraic systems which can have more or less unknown than equations and which can be compatible or not. The second one is referred to an identification problem of a discrete dynamic system whose parameters are unknown and which can be subject to unmodeled dynamics and/or exogenous noise which makes not possible, in general, an exact identification.

Example 4.1 (Moore-Penrose pseudo-inverse) The problem of solving either exactly or approximately a linear system of algebraic equations is very important and it appears in many engineering and scientific applications. It is possible to focus it to the light of best proximity points of non-self-mappings as follows. Consider the linear algebraic system $C x=e$ where $C \in \mathbf{R}^{n \times p}$ (a real matrix of order $n \times p$ ) and $e \in \mathbf{R}^{p}$. It is known from the 
Rouché-Frobenius theorem from Linear Algebra that a solution $x \in \mathbf{R}^{p}$ exists if $\operatorname{rank}(C, e)=$ rank $C$. The solution is unique given by $x=C^{-1} e$ if $p=n$, and $\operatorname{rank} C=p$ with the algebraic system being determined compatible. If $\operatorname{rank}(C, e)=\operatorname{rank} C=q \leq \min (n, p) \neq n$ then there are infinitely many solutions and the algebraic system is indetermined compatible being, in particular, overdetermined if $n>p$ and undetermined if $n<p$. If $\operatorname{rank}(C, e)>\operatorname{rank} C$ then the algebraic system is incompatible. A more general setting is $C X=E$, where $C \in \mathbf{R}^{n \times p}$, $E \in \mathbf{R}^{n \times q}$ are given and $X \in \mathbf{R}^{p \times q}$ is a solution which exists if and only if $\operatorname{rank} C=\operatorname{rank}(C \vdots E)$. The following cases hold:

(a) If $\operatorname{rank} C=\operatorname{rank}(C: E) \neq p$, then $C^{+} C E \neq E$, and there are infinitely many solutions of the form $X=C^{+} E+\left(I-C^{+} C\right) W$ with $C^{+}$being the Moore-Penrose pseudo-inverse of $C$. The domain of the non-self-mapping $T_{C}: A \rightarrow B$, represented by the matrix $C$, can be restricted to $A=\left\{X=C^{+} E+\left(I-C^{+} C\right) W: W \in \mathbf{R}^{p \times q}\right\}$. To close a proper formalism we extend the matrices in $A$ to matrices $\bar{A} \subset \mathbf{R}^{n \times(\max (p, q)-q)}$ and those in $B$ to $\bar{B} \subset \mathbf{R}^{n \times(\max (p, q)-p)}$ by adding zero columns (if $p \neq q$ either $A \neq \bar{A}$ or $B \neq \bar{B}$ ) and we consider them as subsets of $X \equiv \mathbf{R}^{n \times(\max (p, q)-q)}$ and consider the metric space $(X, d)$ with $d$ being the Euclidean metric so that $D=0$ with the sets of best proximity points of $\bar{A}$ and $\bar{B}$ being:

$$
\begin{aligned}
& \bar{A}_{0}=\bar{A}=\left\{\bar{X}=(X \vdots 0): X=C^{+} E+\left(I-C^{+} C\right) W, W \in \mathbf{R}^{n \times q}, 0 \in \mathbf{R}^{n \times(\max (p, q)-q)}\right\}, \\
& \bar{B}_{0}=\bar{B}=\left\{(E \vdots 0): 0 \in \mathbf{R}^{n \times(\max (p, q)-p)}\right\}
\end{aligned}
$$

$\bar{A}_{0}$ is the set of solutions of the compatible indeterminate algebraic system.

(b) If $\operatorname{rank} C=\operatorname{rank}(C \vdots E)=p$ then the solution $X=C^{+} E$ is unique and $\bar{A}_{0}=\bar{A}=\left\{\left(C^{+} E: 0\right): 0 \in \mathbf{R}^{n \times(\max (p, q)-q)}\right\}$ consist of one element which is the unique solution.

(c) If $\min (p, n) \geq \operatorname{rank} C<\operatorname{rank}(C \vdots E)$ then $C^{+} C E \neq E$ and the algebraic system is incompatible. By considering $(X, d)$ as a Banach space endowed with the Euclidean norm, we can check for the best solution which minimizes $\|C X-E\|$ over $X \in \mathbf{R}^{p \times q}$ if it exists. Such a solution exists in a least-squares sense and it is unique if $n \geq \operatorname{rank} C=p<\operatorname{rank}(C \vdots E)$, since $C^{T} C$ is non-singular, of order $p$, and $C^{+}=\left(C^{T} C\right)^{-1} C^{T}$, and $\hat{X}=\left(C^{T} C\right)^{-1} C^{T} E$ minimizes $\|C X-E\|$ over the set of matrices $X \in \mathbf{R}^{p \times q}$ so that $D=d(\bar{A}, \bar{B})=\left\|\left(\left(C^{T} C\right)^{-1} C^{T}-I\right) E\right\|$, the sets of best proximity points of $\bar{A}$ being

$$
\bar{A}_{0}=\bar{A}=\left\{\bar{X}=(X \vdots 0): X=\left(C^{T} C\right)^{-1} C^{T} E, 0 \in \mathbf{R}^{n \times(\max (p, q)-q)}\right\},
$$

since $\left(I-C^{+} C\right)=0$ and $\bar{B}_{0}$ is as the above one of case (a). $\bar{A}_{0}$ is the best solution of the incompatible algebraic system.

The pseudo-inverse can be calculated without inverting $C^{T} C$ by the iterative process:

$$
C_{n+1}^{+}=\left(2 I-C_{n}^{+} C\right) C_{n}^{+} ; \quad n \in \mathbf{Z}_{+} ; \quad C_{0}^{+} \quad \text { such that } C_{0}^{+} C=\left(C_{0}^{+} C\right)^{*}
$$

(so-called Ben-Israel-Cohen, or hyper-power sequence, iterative method [21]). It follows that $C_{n}^{+} \rightarrow C^{+}$as $n \rightarrow \infty$ since (1) $C^{+}$is unique; and (2) the iterative process satisfies the pseudo-inverse properties $C^{+}=C^{+} C C^{+}$and $C^{+} C=\left(C^{+} C\right)^{*}$ under the replacement $C_{n}^{+} \rightarrow$ 
$C^{+} ; \forall n \in \mathbf{Z}_{0+}$. By using the iterative process, we can also define sequences of sets and associate sequences of distances by:

$$
\begin{aligned}
D_{n} & =d\left(\bar{A}_{n}, \bar{B}\right)=\left\|\left(C_{n}^{+}-I\right) E\right\| \rightarrow D=\left\|\left(C^{+}-I\right) E\right\| \quad \text { as } n \rightarrow \infty, \\
\bar{B}_{0} & =\bar{B}=\left\{(E \vdots 0): 0 \in \mathbf{R}^{n \times(\max (p, q)-p)}\right\}, \\
\bar{A}_{0 n} & =\bar{A}_{n}=\left\{\left(C_{n}^{+} E \vdots 0\right): 0 \in \mathbf{R}^{n \times(\max (p, q)-q)}\right\} \rightarrow \bar{A}_{0} \\
& =\bar{A}=\left\{\left(C^{+} E \vdots 0\right): 0 \in \mathbf{R}^{n \times(\max (p, q)-q)}\right\} \quad \text { as } n \rightarrow \infty ;
\end{aligned}
$$

$\bar{B}_{0}$ and $\bar{A}_{0 n}$ are unique, if the pseudo-inverse $C^{+}=\left(C^{T} C\right)^{-1} C^{T}$ exists for the given initial $C_{0}^{+}$. However, if $\operatorname{rank} C=\operatorname{rank}(C: E) \neq p$, so that $E \neq C_{n}^{+} C_{n} E$ (case (a) - incompatible algebraic system) then if we use the iterative procedure:

$$
\begin{aligned}
C_{n+1}^{+} & =\left(2 I-C_{n}^{+} C\right) C_{n}^{+} ; \quad n \in \mathbf{Z}_{+} ; \quad C_{0}^{+} \quad \text { such that } C_{0}^{+} C=\left(C_{0}^{+} C\right)^{*}, \\
\bar{A}_{0 n} & =\bar{A}_{0 n}\left(W_{n}\right) \\
& =\left\{\bar{X}_{n}=\left(X_{n} \vdots 0\right): X_{n}=C_{n}^{+} E+\left(I-C_{n}^{+} C_{n}\right) W_{n}, W_{n} \in \mathbf{R}^{n \times q}, 0 \in \mathbf{R}^{n \times(\max (p, q)-q)}\right\}
\end{aligned}
$$

is a non-unique set of arbitrary solutions of the incompatible algebraic system of which the best (error-norm minimizing) solution is the unique one described above. For initial conditions satisfying $C_{0}^{+} C=\left(C_{0}^{+} C\right)^{*}$, for instance, $C_{0}^{+}=\left(C^{*} C+\delta I\right)^{-1} C^{*}, \delta \in \mathbf{R}^{+}$, the pseudo-inverse converges quadratically to its limit, that is, $\lim _{n \rightarrow \infty} \frac{\left\|C_{n+1}^{+}-C^{+}\right\|}{\left\|C_{n+1}^{+}-C^{+}\right\|^{2}}=\rho>0$. Furthermore,

$$
D_{n}=\left\|x_{n+1}-C x_{n}\right\|=\left\|x_{n+1}-C C_{n}^{+} E\right\| ; \quad \forall n \in \mathbf{Z}_{0+}
$$

and, since the convergence of the pseudo-inverse is quadratic, there is a bounded positive sequence $\left\{\rho_{n}\right\} \rightarrow \rho$ such that since $\left\{x_{n}\right\},\left\{y_{n}\right\} \rightarrow x^{*}=C^{+} E$, since the pseudo-inverse is unique when it exists; we have

$$
\begin{aligned}
\left\|x_{n+1}-y_{n+1}\right\| & \leq\left\|\left(C_{n+1}^{+}\left(x_{0}\right)-C^{+}+C^{+}-C_{n+1}^{+}\left(y_{0}\right)\right) b\right\| \\
& \leq\left(\rho_{n}\left\|\left(C_{n}^{+}\left(x_{0}\right)-C^{+}+C^{+}-C_{n}^{+}\left(y_{0}\right)\right) b\right\|\right)\left\|\left(C_{n}^{+}\left(x_{0}\right)-C^{+}+C^{+}-C_{n}^{+}\left(y_{0}\right)\right) b\right\| \\
& \leq\left(\rho_{n}\left\|\left(C_{n}^{+}\left(x_{0}\right)-C_{n}^{+}\left(y_{0}\right)\right) b\right\|\right)\left(\left\|x_{n}-x^{*}-y_{n}+x^{*}\right\|\right) \\
& \leq \rho_{n} \varepsilon\left(\left\|x_{n}-y_{n}\right\|\right) ; \quad \forall n\left(\geq n_{0}\right) \in \mathbf{Z}_{0+}
\end{aligned}
$$

for any given $\varepsilon \in \mathbf{R}^{+}$any $n\left(\geq n_{0}\right) \in \mathbf{Z}_{0+}$ and some $n_{0}=n_{0}(\varepsilon) \in \mathbf{Z}_{0+}$. Since the choice of $\varepsilon$ is arbitrary, the iterative process is an asymptotic proximal contraction since, for any given real $\rho_{1} \in(0,1)$ there is $n_{01}=n_{01}\left(\varepsilon, \rho_{1}\right) \in \mathbf{Z}_{0+}$ such that $\rho_{n} \varepsilon \leq \rho_{1} ; \forall n\left(\geq n_{01}\right) \in \mathbf{Z}_{0+}$.

Example 4.2 (Parametrical estimation of an uncertain discrete dynamic system) Consider $d: X \times X \rightarrow \mathbf{R}_{0+}$ to be a homogeneous translation-invariant metric and two nonempty sequences of closed subsets $\left\{A_{0 n}\right\}$ and $\left\{B_{0 n}\right\}$ of $X$, with $A_{0 n} \cap B_{0 n} \neq \varnothing$ with mutual distances $D_{n}^{0}=d\left(A_{0 n}, B_{0 n}\right) ; \forall n \in \mathbf{Z}_{0+}$ such that each proximal set $A_{0 n}^{0} \subset A_{0 n}$ of $A_{0 n}$ to 
$B_{0 n}$ is non-empty; $\forall n \in \mathbf{Z}_{0+}$. Now, built $\left\{x_{n}\right\} \subset A_{0 n}$ being a nominal proximal sequence to $B_{0 n}$ constructed such that, given a proximal mapping $T: \bigcup_{j \in \mathbf{Z}_{0+}} A_{0 j} \rightarrow \bigcup_{j \in \mathbf{Z}_{0+}} B_{0 j}$ with non-empty images of its restrictions $T: \bigcup_{j \in \mathbf{Z}_{0+}} A_{0 j}\left|A_{0 n} \rightarrow \bigcup_{j \in \mathbf{Z}_{0+}} B_{0 j}\right| B_{0 n} ; \forall n \in \mathbf{Z}_{0+}$, that is $T\left(A_{0 n}\right) \subset B_{0 n}$ for any $n \in \mathbf{Z}_{0+}$ is non-empty, then $d\left(x_{n+1}, T x_{n}\right)=D_{n}^{0} ; \forall n \in \mathbf{Z}_{0+}$. We also consider a sequence of proximal mappings $T_{n}: \bigcup_{j \in \mathbf{Z}_{0_{+}}} A_{j} \rightarrow \bigcup_{j \in \mathbf{Z}_{0_{+}}} B_{j}$ for sequences of closed subsets $\left\{A_{n}\right\}$ and $\left\{B_{n}\right\}$ of $X$, with $A_{n} \cap B_{n} \neq \varnothing$ with mutual distances $D_{n}=d\left(A_{0 n}, B_{0 n}\right)$; $\forall n \in \mathbf{Z}_{0+}$ such that each set of best proximity points $A_{n}^{0} \subset A_{n} \subseteq A_{0 n}$ of $A_{n}$ to $B_{n}$ is nonempty; $\forall n \in \mathbf{Z}_{0+}$. Build a proximal sequence $\left\{y_{n}\right\} \subset A_{n}$ to $B_{n}$ constructed such that, given a sequence $\left\{T_{n}\right\}$ of proximal mappings $T_{n}: \bigcup_{j \in \mathbf{Z}_{0+}} A_{j} \rightarrow \bigcup_{j \in \mathbf{Z}_{0+}} B_{j}$ with non-empty images of its restrictions $T: \bigcup_{j \in \mathbf{Z}_{0+}} A_{j}\left|A_{n} \rightarrow \bigcup_{j \in \mathbf{Z}_{0+}} B_{j}\right| B_{n}$, then $d\left(y_{n+1}, T_{n} y_{n}\right)=D_{n+1} ; \forall n \in \mathbf{Z}_{0+}$. Define sequences of measured and operator errors as follows:

$$
\tilde{x}_{n}=y_{n}-x_{n} ; \quad \widetilde{T}_{n}=T_{n}-T ; \quad \forall n \in \mathbf{Z}_{0+},
$$

which can be associated with a parametrical identification problem of a discrete dynamic system, where $\left\{x_{n}\right\}$ is the sequence of measured data, or measurable output, of the identified system and $\left\{y_{n}\right\}$ is the corresponding data given by the identifier, i.e. the sequence of adjustable data, which is a recursive parameter estimator [22-24]. Then the following distance constraints for the best proximity points of the identified system and its associate estimator, operators, parameters, and sequences are relevant to the studied problem:

$$
\begin{aligned}
& d\left(x_{n+1}, T x_{n}\right)=D_{n+1}^{0}, \quad d\left(y_{n+1}, T_{n} y_{n}\right)=D_{n+1}, \\
& T_{n}=T+\widetilde{T}_{n} ; \quad y_{n+1}=x_{n+1}+\tilde{x}_{n+1}, \quad \tilde{x}_{n+1}=\hat{y}_{n+1}-y_{n+1}, \\
& \hat{y}_{n+1}=\hat{\theta}_{n}^{T} x_{n}=\left(\hat{\theta}_{n}^{T}, 0^{T}\right)\left(x_{n}^{0 T}, x_{n}^{\prime T}\right)^{T}=T_{n} x_{n}=\hat{T}_{n} x_{n}^{0}, \\
& y_{n+1}^{0}=\bar{\theta}^{T} x_{n}=\left(\theta^{T}, \theta^{\prime T}\right)\left(x_{n}^{0 T}, x_{n}^{\prime T}\right)^{T}=\hat{T} x_{n}^{0}+\hat{T}^{\prime} x_{n}^{\prime}+d_{n}^{0}=\hat{T} x_{n}+d_{n}^{0} ;
\end{aligned}
$$

$\forall n \in \mathbf{Z}_{0+}$, where the superscript ' $T$ ' stands for transposition, is the measured output of the real process, and $\theta, \theta^{\prime}$ are parameters of the modeled and unmodeled dynamics of the discrete dynamic system provided it is linear in the parameters; $\left\{\hat{\theta}_{n}\right\}$ is an estimated sequence of the parameter vector $\theta$ of the modeled part, $d_{n}^{0}$ is the internal noise, $\hat{T}$ is the auto-regression operator which provides the nominal output; $\hat{T}_{n}$ is the auto-regression operator which provides the nominal value of the output from the nominal part $x_{n}^{0}$ of the whole process regressor $x_{n}$, where $x_{n}=\left(x_{n}^{0 T}, x_{n}^{\prime T}\right)^{T}$, such that $x_{n}^{0}$ is the nominal regressor (that is, the regressor of the modeled dynamics), $x_{n}$ is the regressor associated with the unmodeled dynamics, and $\hat{T}^{\prime}$ is the auto-regressor operator which supplies the contribution of the unmodeled dynamics of the system to the measured output. Note that the above metric space can also be considered a normed space when endowed with the metric-induced norm since the metric is homogeneous and translation-invariant.

Remark 4.3 The subsequent equations describe the identification process when the identified process is linear in the parameters as well as the estimation parallel process. Thus, the measured output and estimated output sequences, respectively, $y_{n}^{0}, \hat{y}_{n}$ are real scalar products of a parameter vector, respectively, $\theta, \hat{\theta}_{n}$ by their associated regressors, respectively, $x_{n}^{0}, x_{n}^{\prime}$ which are associated with previous values which depend on the order of the modeled and unmodeled parts of system. All the parameters $\theta$ (parameter vector 
of the modeled part) and $\theta^{\prime}$ (parameter vector of the unmodeled part) are assumed to be unknown in the most general framework, the first one being estimated by the estimation algorithm. The dimension of $\theta$, so that its estimation $\hat{\theta}_{n}$, are known while that of $\theta^{\prime}$ is unknown, in general. The updating process of the estimation is of the form $\hat{\theta}_{n+1}=\hat{\theta}_{n+1}\left(\hat{\theta}_{n}, y_{n+1}^{0}, \hat{y}_{n+1}, x_{n}^{0}\right) ; n \in \mathbf{Z}_{0+}$ and it is performed through an algorithm, like for instance, recursive or batch, least-squares type algorithms. The unmodeled parameters, i.e. the components of $\theta^{\prime}$ are not estimated. Thus, there are three sources of identification error in the process, that is, the error between the identified system and its identified counterpart (or parametrical identification algorithm), namely, (a) the fact that $\theta$ is unknown so that the nominal parametrical error $\tilde{\theta}_{n}=\hat{\theta}_{n}-\theta\left(n \in \mathbf{Z}_{0_{+}}\right)$is nonzero, in general; (b) the eventual presence of output exogenous additive noise $d_{n}\left(n \in \mathbf{Z}_{0_{+}}\right)$; (c) the presence of unmodeled dynamics for which no parametrical estimation algorithm is included. The whole identification process can also be described through linear operators defined to the light of the formalism of Section 2. Such a description is also incorporated in the sequel under the form of equalities to the linear parametrical description. It can be pointed out that this alternative parallel description is also useful to describe nonlinear processes by the appropriate definitions of the operators describing the trajectory sequences as $T, T_{n}$, and their auxiliary ones for the modeled and unmodeled dynamics.

The identified process and its estimation algorithm are described through the equations below in the particular case that the identified process and the estimator are in a parallel operation so that they share a common regressor $x_{n}$ :

$$
\begin{aligned}
& x_{n+1} \equiv\left(x_{n}^{0 T}, x_{n}^{\prime T}\right)^{T}=\left(y_{n+1}^{0}, E_{1}\left(x_{n}^{0}, x_{n}^{\prime}\right)^{T}\right)^{T} \\
& =\left(\hat{T} x_{n}^{0}+\hat{T}^{\prime} x_{n}^{\prime}+d_{n}^{0}, E_{1}\left(x_{n}^{0}, x_{n}^{\prime}\right)^{T}\right)^{T} \equiv T x_{n}+d_{n}, \\
& y_{n+1}=\left(\hat{y}_{n+1}, E_{1}\left(x_{n}^{0}, x_{n}^{\prime}\right)^{T}\right)^{T}=\left(\hat{T}_{n} x_{n}^{0}, E_{1}\left(x_{n}^{0}, x_{n}^{\prime}\right)^{T}\right)^{T} \equiv T_{n} x_{n}, \\
& \tilde{x}_{n+1}=\left(\hat{y}_{n+1}-y_{n+1}, 0^{T}\right)^{T}=\left(\tilde{\theta}_{n}^{T} x_{n}^{0}-\theta^{\prime T} x_{n}^{\prime}, 0^{T}\right)^{T} ; \quad \tilde{\theta}_{n}=\hat{\theta}_{n}-\theta \\
& =\left(\left(\hat{T}_{n}-\hat{T}\right) x_{n}^{0}-\hat{T}^{\prime} x_{n}^{\prime}-d_{n}^{0}, 0^{T}\right)^{T}=\left(\widetilde{\hat{T}}_{n} x_{n}^{0}-\hat{T}^{\prime} x_{n}^{\prime}-d_{n}^{0}, 0^{T}\right)^{T} \\
& =T_{n} x_{n}-T x_{n}-d_{n}=T_{n} \tilde{x}_{n}-d_{n}, \\
& d_{n}=\left(d_{n}^{0}, 0^{T}\right)^{T} ; \quad \tilde{\theta}_{n}=\hat{\theta}_{n}-\theta ; \quad \widetilde{T}_{n}=T_{n}-T ; \quad \widetilde{\hat{T}}_{n}=\hat{T}_{n}-\hat{T}, \\
& \widetilde{T}_{n} x_{n}-d_{n}=\left(T_{n}-T\right) x_{n}=\left(\left(\hat{T}_{n}-\hat{T}\right) x_{n}^{0}-\hat{T}^{\prime} x_{n}^{\prime}-d_{n}^{0}, 0^{T}\right)^{T} \\
& =\left(\tilde{\theta}_{n}^{T} x_{n}^{0}-\theta^{\prime T} x_{n}^{\prime}-d_{n}^{0}, 0^{T}\right)^{T}, \\
& \widetilde{T}_{n+1} x_{n+1}+d_{n+1}=\left(T_{n+1}-T\right) x_{n+1}=\left(T_{n+1}-T\right)\left(T x_{n}+d_{n}\right) \\
& =\left(T_{n+1}-T\right)\left(\hat{T} x_{n}^{0}+\hat{T}^{\prime} x_{n}^{\prime}+d_{n}^{0}, E_{1}\left(x_{n}^{0}, x_{n}^{\prime}\right)^{T}\right)^{T} ;
\end{aligned}
$$

$\forall n \in \mathbf{Z}_{0+}$ and $E_{1}=(I \vdots 0)$ is a rectangular matrix with a number of rows equalizing that of the columns less one which loses the last value of the regressor of the preceding sample. In real identification situations, we see that:

(a) $\hat{T}_{n}, x_{n}^{0}$ - are both known;

(b) $x_{n}$ - the whole regressor, which includes the contribution of the unmodeled dynamics, is partially unknown, since the sub-vector $x_{n}^{\prime}$ of $x_{n}$ is of unknown dimension since the order of the unmodeled dynamics contribution is unknown; 
(c) $T, \hat{T}, \hat{T}^{\prime}$ - are unknown or not precisely known;

(d) $T_{n}$ - is known; $d_{n}^{0}$ - is unknown;

(e) $y_{n}^{0}, \hat{y}_{n}$ - are known, the first one by direct measurement, and the second one since it is generated by the estimation algorithm.

The following sequences are relevant for the identification problem $\tilde{x}_{n}=y_{n}-x_{n} ; \widetilde{T}_{n}=$ $T_{n}-T ; \forall n \in \mathbf{Z}_{0+}$ so that we also define

$$
\begin{aligned}
g_{n+1} & =d\left(0, \widetilde{T}_{n} x_{n}\right)+d\left(\tilde{x}_{n+1}, T \tilde{x}_{n}\right)+d\left(0, \widetilde{T}_{n} \tilde{x}_{n}\right) \\
& =d\left(0, \widetilde{T}_{n} x_{n}\right)+d\left(T_{n} \tilde{x}_{n}, T \tilde{x}_{n}+d_{n}\right)+d\left(0, \widetilde{T}_{n} \tilde{x}_{n}\right) \leq \bar{g}_{n+1} \\
& =d\left(0, \widetilde{T}_{n} x_{n}\right)+d\left(T_{n} \tilde{x}_{n}, T \tilde{x}_{n}\right)+d\left(T \tilde{x}_{n}, T \tilde{x}_{n}+d_{n}\right)+d\left(0, \widetilde{T}_{n} \tilde{x}_{n}\right) ; \quad \forall n \in \mathbf{Z}_{0+}
\end{aligned}
$$

so that, related to the results of Section 2, Lemma 2.2, we can adjust the estimation algorithm sequences to the real data according to the following distance best proximity constraints:

$$
\begin{aligned}
d\left(y_{n+1}, T_{n} y_{n}\right) & =D_{n+1}=d\left(x_{n+1}+\tilde{x}_{n+1}, T_{n} x_{n}+T_{n} \tilde{x}_{n}\right) \\
& \leq d\left(x_{n+1}, T_{n} x_{n}\right)+d\left(T_{n} x_{n}, T_{n} x_{n}+T_{n} \tilde{x}_{n}-\tilde{x}_{n+1}\right) \\
& \leq d\left(x_{n+1}, T x_{n}\right)+d\left(T x_{n}, T x_{n}+\widetilde{T}_{n} x_{n}\right)+d\left(\tilde{x}_{n+1}, T_{n} \tilde{x}_{n}\right) \\
& \leq d\left(x_{n+1}, T x_{n}\right)+d\left(0, \widetilde{T}_{n} x_{n}\right)+d\left(\tilde{x}_{n+1}, T \tilde{x}_{n}\right)+d\left(T \tilde{x}_{n}, T \tilde{x}_{n}+\widetilde{T}_{n} \tilde{x}_{n}\right) \\
& \leq D_{n+1}^{0}+d\left(0, \widetilde{T}_{n} x_{n}\right)+d\left(0, \widetilde{T}_{n} \tilde{x}_{n}\right)+d\left(T_{n} \tilde{x}_{n}, T \tilde{x}_{n}\right)+d\left(T \tilde{x}_{n}, T \tilde{x}_{n}+d_{n}\right) \\
& =D_{n+1}^{0}+g_{n+1} ; \quad \forall n \in \mathbf{Z}_{0+}, \\
d\left(x_{n+1}, T x_{n}\right)= & D_{n+1}^{0}=d\left(y_{n+1}-\tilde{x}_{n+1}, T y_{n}-T \tilde{x}_{n}\right) \\
& \leq d\left(y_{n+1}, T y_{n}\right)+d\left(T \tilde{x}_{n}, \tilde{x}_{n+1}\right) \\
& \leq D_{n+1}+d\left(\widetilde{T}_{n} x_{n}, 0\right)+d\left(\widetilde{T}_{n} \tilde{x}_{n}, 0\right)+d\left(T \tilde{x}_{n}, T_{n} \tilde{x}_{n}-d_{n}\right) \\
& \leq D_{n+1}+g_{n+1} ; \quad \forall n \in \mathbf{Z}_{0+},
\end{aligned}
$$

then

$$
\begin{aligned}
& \max \left(D_{n}-g_{n}, 0\right) \leq D_{n}^{0} \leq D_{n}+g_{n}, \\
& \max \left(D_{n}^{0}-g_{n}, 0\right) \leq D_{n} \leq D_{n}^{0}+g_{n} ; \quad \forall n \in \mathbf{Z}_{0+} .
\end{aligned}
$$

If $g_{n} \rightarrow 0$ as $n \rightarrow \infty$, i.e. if all the uncertainty sources of noise/unmodeled dynamics and the identification error between the true process vanish asymptotically and the identifier $\left\{\widetilde{\hat{T}}_{n}\right\} \rightarrow 0$ uniformly, then $\left\{\hat{T}_{n}\right\} \rightarrow \hat{T}$ uniformly, $\hat{T}^{\prime}=0$, then $\left|D_{n}^{0}-D_{n}\right| \rightarrow 0$ as $n \rightarrow \infty$ and $\left\{D_{n}^{0}\right\},\left\{D_{n}\right\} \rightarrow D=0$. For $\left\{D_{n}^{0}\right\} \rightarrow D$, it suffices $\left\{\left\|d_{n}\right\|\right\} \rightarrow D$ from (4.6) with $D=0$ if and only if $\left\{d_{n}\right\} \rightarrow 0$, that is, if $\left\{d_{n}^{0}\right\} \rightarrow 0$. However, if $\hat{T}^{\prime}$ is not the zero operator (in the linear case, if the parameter vector of the unmodeled dynamics $\theta^{\prime}$ is nonzero), then even if $\left\{\hat{T}_{n}\right\} \rightarrow \hat{T}$ uniformly (perfect asymptotic identification of the modeled dynamics - in the linear case $\left\{\hat{\theta}_{n}\right\} \rightarrow \theta$, equivalently $\left.\left\{\tilde{\theta}_{n}\right\} \rightarrow 0\right)$ and $\left\{\left\|d_{n}^{0}\right\|\right\}$ converges, it can happen that $\left\{D_{n}\right\}$ does not converge in the sense that the best proximity points of the identifier are not subject to a set distance which converges. Typically, in the linear case with a scalar measurement, there is 
an identification error of the form

$$
d\left(x_{n+1}, y_{n+1}\right)=\left\|x_{n+1}-y_{n+1}\right\|=-\tilde{\theta}_{n}^{T} x_{n}^{0}+f\left(\theta^{\prime}, x_{n}^{\prime}, d_{n}^{0}\right) ; \quad \forall n \in \mathbf{Z}_{0+}
$$

[9-11], which does not converge to zero asymptotically, in general, except if $f \equiv 0$, and $\left\{T_{n}\right\}$ is not a proximal contraction. The relevant equations for the identification process are (4.10a), in the general case, and (4.10b) in the linear-in-the parameters case, provided that the measured data sequence is scalar (i.e. the first component of the regressor). It is observed that a sufficient condition guaranteeing $\left\{\widetilde{T}_{n} x_{n}-\widetilde{T}_{n+1} x_{n+1}\right\} \rightarrow 0$ is:

(a) $\left\{d_{n}\right\} \rightarrow d$.

(b) $\left\{T^{\prime} x_{n}^{\prime}\right\} \rightarrow x_{e}^{\prime}$, that is, the contribution of the unmodeled dynamics vanishes asymptotically to an equilibrium. There are typically two situations for that to happen, namely, (b1) $T^{\prime} \equiv 0$, that is, the process is perfectly modeled so that the order of its whole dynamics is known. This occurs very seldom in controlled processes which have to work under very different or changing operation conditions along large time intervals, (b2) the unmodeled dynamics process converges to an asymptotically stable partial equilibrium $x_{e}^{\prime}$.

(c) $\left\{\hat{T}_{n}\right\} \rightarrow T$ uniformly under the updating estimation algorithm $\hat{T}_{n+1}=\hat{T}_{n+1}\left(\hat{T}_{n} x_{n}, y_{n+1}^{0}\left(d_{n+1}^{0}\right)\right) ; \forall n \in \mathbf{Z}_{0+}$ employed under a given initialization, i.e., there is a perfect asymptotic identification of the modeled dynamics achieved. Again, it is difficult in practice to achieve the perfect identification objective of the modeled dynamics, even if $\left\{d_{n}\right\} \rightarrow d$ and $\left\{T^{\prime} x_{n}^{\prime}\right\} \rightarrow x_{e}^{\prime}$ unless $d=0$ and $x_{e}^{\prime}=0$.

Note that the property $\left\{\widetilde{T}_{n} x_{n}-\widetilde{T}_{n+1} x_{n+1}\right\} \rightarrow 0$ does not ensure that the error operator sequence $\left\{\widetilde{T}_{n}\right\}$ converges to a proximal contraction but the result is obtained that the equations of best proximity points (4.2) hold with asymptotic convergence and asymptotic convergence of the distance sequences $\left\{D_{n}^{0}\right\},\left\{D_{n}\right\} \rightarrow 0$.

Competing interests

The authors declare that they have no competing interests.

Authors' contributions

All authors contributed equally to the writing of this paper. All authors read and approved the final manuscript.

\section{Author details}

1 Institute of Research and Development of Processes, University of the Basque Country, Campus of Leioa (Bizkaia), Barrio Sarriena, P.O. Box 644, Bilbao, Leioa 48940, Spain. ²Department of Mathematics, Texas A\&M University-Kingsville, 700 University Blvd., Kingsville, TX 78363-8202, USA. ${ }^{3}$ Department of Mathematics, Faculty of Science, King Abdulaziz University, Jeddah, 21589, Saudi Arabia. ${ }^{4}$ Department of Telecommunications and Systems Engineering, Universitat Autònoma de Barcelona, Bellaterra, Barcelona, 08193, Spain.

\section{Acknowledgements}

Professor De la Sen and Professor Ibeas are grateful to the Spanish Government for its support of this research with Grant DPI2012-30651, and to the Basque Government for its support of this research trough Grants IT378-10 and SAIOTEK S-PE12UN015. They are also grateful to the University of Basque Country for its financial support through Grant UFI 2011/07. The author Manuel De la Sen is very grateful to Dr. S Born, Dr. D Grubb, Dr. M Cichon, Dr. A Szaz, Dr. G Oman, Dr. U Mutze and Dr. P Bankston for their useful comments, opinions and mutual discussions concerning the local finiteness property, Alexandrov spaces, P-spaces and other related points of view about the closeness of countable unions of closed sets. Finally, the authors thank the referees for their suggestions to improve the first version of the manuscript.

Received: 4 May 2014 Accepted: 22 July 2014 Published: 18 August 2014

\section{References}

1. Sadiq-Basha, S: Best proximity points: optimal solutions. J. Optim. Theory Appl. 151, 210-216 (2011)

2. Berinde, $\mathrm{V}$ : Approximating fixed points of weak contractions using the Picard iteration. Nonlinear Anal. Forum 9 , 43-53 (2004)

3. Gabeleh, M: Best proximity points for weak proximal contractions. Bull. Malays. Math. Soc. (in press) 
4. Samet, B: Some results on best proximity points. J. Optim. Theory Appl. 159(1), 281-291 (2013)

5. Eldred, AA, Veeramani, P: Existence and convergence of best proximity points. J. Math. Anal. Appl. 323, 1001-1006 (2006)

6. Jleli, M, Samet, B: Best proximity points for $\alpha$ - $\psi$-proximal contractive type mappings and applications. Bull. Sci. Math. 137(8), 977-995 (2013)

7. De la Sen, M: Linking contractive self-mappings and cyclic Meir-Keeler contractions with Kannan self-mappings. Fixed Point Theory Appl. 2010, Article ID 572057 (2010). doi:10.1155/2010/572057

8. Chen, C-M, Chen, $\mathrm{CH}$ : Best periodic proximity points for cyclic weaker Meir-Keeler contractions. Fixed Point Theory Appl. 2012, 79 (2012)

9. De la Sen, M: Some combined relations between contractive mappings, Kannan mappings, reasonable expansive mappings and T-stability. Fixed Point Theory Appl. 2009, Article ID 815637 (2009). doi:10.1155/2009/815637

10. De la Sen, M, Agarwal, RP: Some fixed point-type results for a class of extended cyclic self-mappings with a more general contractive condition. Fixed Point Theory Appl. 2011, 59 (2011)

11. De la Sen, M, Agarwal, RP, Nistal, R: Non-expansive and potentially expansive properties of two modified $p$-cyclic self-maps in metric spaces. J. Nonlinear Convex Anal. 14(4), 661-686 (2013)

12. Hussain, $\mathrm{N}$ : Common fixed points in best approximations for Banach operator pairs with Ćirić type /-contractions. J. Math. Anal. Appl. 338(2), 1351-1363 (2008)

13. Mongkolkeha, C, Cho, YJ, Kumam, P: Best proximity points for generalized proximal C-contraction mappings in metric spaces with partial orders. J. Inequal. Appl. 2013, 94 (2013)

14. Basha, SS, Shahzad, N: Best proximity point theorems for generalized proximal contractions. Fixed Point Theory Appl. 2012, 42 (2012)

15. Abkar, A, Gabeleh, M: Best proximity points for asymptotic cyclic contraction mappings. Nonlinear Anal., Theory Methods Appl. 74(18), 7261-7268 (2011)

16. De la Sen, M: About robust stability of dynamic systems with time-delays through fixed point theory. Fixed Point Theory Appl. 2008, Article ID 480187 (2008). doi:10.1155/2008/480187

17. Mishra, SN, Singh, SL, Pant, R: Some new results on stability of fixed points. Chaos Solitons Fractals 45(7), $2012-2016$ (2012)

18. De la Sen, M: About robust stability of Caputo linear fractional dynamic systems with time delays through fixed point theory. Fixed Point Theory Appl. 2011, Article ID 867932 (2011). doi:10.1155/2011/867932

19. Gabeleh, M: Best proximity point theorems via proximal non-self mappings. J. Optim. Theory Appl. (2014). doi:10.1007/s10957-014-0585-8

20. Engelking, R: General Topology. Sigma Series in Pure Mathematics, vol. 6. Heldermann, Berlin (1989)

21. Ben-Israel, A, Greville, TNE: Generalized Inverses: Theory and Applications, 2nd edn. Springer, Heidelberg (2003)

22. Bilbao-Guillerna, A, De la Sen, M, Ibeas, A, Alonso-Quesada, S: Robustly stable multiestimation scheme for adaptive control and identification with model reduction issues. Discrete Dyn. Nat. Soc. 2005(1), 31-67 (2005). doi:10.1155/DDNS.2005.31

23. Alonso-Quesada, S, De la Sen, M: Robust adaptive control of discrete nominally stabilizable plants. Appl. Math. Comput. 150(2), 555-583 (2004)

24. De la Sen, M: Adaptive stabilization of first-order systems using estimates modification based on a Sylvester determinant test. Comput. Math. Appl. 37(10), 51-62 (1999)

\section{Submit your manuscript to a SpringerOpen ${ }^{\circ}$ journal and benefit from:}

- Convenient online submission

- Rigorous peer review

- Immediate publication on acceptance

- Open access: articles freely available online

- High visibility within the field

- Retaining the copyright to your article 